\title{
The Fanconi Anemia/BRCA pathway: new faces in the crowd
}

\author{
Richard D. Kennedy and Alan D. D'Andrea ${ }^{1}$ \\ Department of Radiation Oncology, Dana-Farber Cancer Institute, Harvard Medical School, \\ Boston, Massachusetts 02115, USA
}

Over the past few years, study of the rare inherited chromosome instability disorder, Fanconi Anemia (FA), has uncovered a novel DNA damage response pathway. Through the cooperation of multiple proteins, this pathway regulates a complicated cellular response to DNA cross-linking agents and other genotoxic stresses. In this article we review recent data identifying new components of the FA pathway that implicate it in several aspects of the DNA damage response, including the direct processing of DNA, translesion synthesis, homologous recombination, and cell cycle regulation. We also discuss new findings that explain how the FA pathway is regulated through the processes of ubiquitination and deubiquitination. We then consider the clinical implications of our current understanding of the FA pathway, particularly in the development and treatment of malignancy in heterozygous carriers of FA mutations or in patients with sporadic cancers. We consider how recent studies of p53-mediated apoptosis and loss of p53 function in models of FA may help explain the clinical features of the disease and finally present a hypothesis to account for the specificity of the FA pathway in the response to DNA cross-links.

Fanconi Anemia (FA) is a rare autosomal recessive and $\mathrm{X}$-linked disorder characterized by congenital abnormalities, progressive bone marrow failure, and cancer susceptibility (Joenje and Patel 2001; Bagby Jr. 2003; D'Andrea and Grompe 2003). Cells derived from FA patients demonstrate chromosomal instability and heightened sensitivity to DNA cross-linking agents, such as mitomycin C (MMC) (German et al. 1987), diepoxybutane (DEB) (Auerbach 1988), and cisplatin (CDDP) (Poll et al. 1985), a feature that is used to make the diagnosis. Most patients will develop bone marrow failure and can develop acute leukemia. Those who survive to adulthood typically develop solid tumors that are usually squamous cell carcinomas of the head and neck or gynecologic system (Alter 1996; Alter et al. 2003).

[Keywords: BRCA; cancer; chemotherapy; DNA cross-links; DNA helicase; Fanconi Anemia]

${ }^{1}$ Corresponding author.

E-MAIL alan_dandrea@dfci.harvard.edu; FAX (617) 632-5757.

Article and publication are at http://www.genesdev.org/cgi/doi/10.1101/ gad.1370505.
FA is a genetically heterogeneous disease and has been traditionally classified using cell fusion experiments that correct sensitivity to DNA cross-linking agents such as MMC. To date at least 12 complementation groups (A, B, C, D1, D2, E, F, G, I, J, L, M) have been identified (Table 1). Complementation groups $A, C$, and $\mathrm{G}$ are the most prevalent accounting for approximately $60 \%, 15 \%$, and $10 \%$ of patients, respectively (Strathdee et al. 1992a; Lo Ten Foe et al. 1996; de Winter et al. 1998). The genes for 11 of the complementation groups have been cloned, and 10 of the proteins have been demonstrated to cooperate in a common biochemical pathway. Disruption of the FA pathway results in the common clinical and cellular phenotype observed in FA.

\section{The basic FA pathway}

During the S phase of the cell cycle, DNA is duplicated by DNA polymerases at multiple replication forks. DNA lesions that disrupt chromatin structure, such as chemically induced cross-links, result in a failure of the replication fork to proceed. As will be discussed later in this article, current evidence suggests that the FA pathway is activated and is required for the response to stalled replication forks. For the purposes of description it is easiest to consider the FA pathway as containing two main complexes, the nuclear E3 monoubuiquitin ligase core complex (referred to as complex 1 in this review) and the chromatin-associated FANCD2/BRCA2 DNA repair complex (referred to as complex 2). As part of the response to a stalled replication fork, complex 1 may be largely involved in the detection and signaling of the stalled replication fork through monoubiquitination of FANCD2 whereas complex 2 may be predominantly involved in the process of DNA repair. It is important to note that the distinction between complex 1 and complex 2 is arbitrary and reflects a recognizable transition in the FA pathway (the monoubiquitination of FANCD2). In fact, there may be one large complex containing all of the subunits of complexes 1 and 2 .

We will now give a brief overview of the entire Fanconi pathway and recently identified components before considering the structures and functions of complex 1 and complex 2 in more detail. Complex 1, the monoubiquitin E3 ligase complex, or core complex, consists of 
Table 1. FA complementation groups and FA genes

\begin{tabular}{|c|c|c|c|c|c|}
\hline $\begin{array}{l}\text { FA } \\
\text { complementation } \\
\text { group }\end{array}$ & FA gene & $\begin{array}{l}\text { Approximate frequency } \\
\text { in FA patients }(\%)\end{array}$ & $\begin{array}{c}\text { Chromosomal } \\
\text { location }\end{array}$ & $\begin{array}{c}\text { Protein product } \\
(\mathrm{kDa})\end{array}$ & Reference \\
\hline A & FANCA & $60 \%$ & $16 \mathrm{q} 24.3$ & 163 & Lo Ten Foe et al. 1996 \\
\hline B & $F A N C B$ & Rare & $\mathrm{Xp} 22.31$ & 95 & Meetei et al. 2004 \\
\hline $\mathrm{C}$ & FANCC & $15 \%$ & $9 q 22.3$ & 63 & Strathdee et al. 1992b \\
\hline D1 & $B R C A 2$ & $5 \%$ & $13 \mathrm{q} 12.3$ & 380 & Howlett et al. 2002 \\
\hline $\mathrm{D} 2$ & FANCD2 & $5 \%$ & 3 p25.3 & 155,162 & Timmers et al. 2001 \\
\hline $\mathrm{E}$ & FANCE & Rare & $6 \mathrm{p} 21.3$ & 60 & de Winter et al. 2000a \\
\hline $\mathrm{F}$ & $F A N C F$ & Rare & $11 \mathrm{p} 15$ & 42 & de Winter et al. 2000b \\
\hline G & FANCG & $10 \%$ & $9 \mathrm{p} 13$ & 68 & de Winter et al. 1998 \\
\hline I & Unknown & Rare & Unknown & Unknown & Unknown \\
\hline J & $B R I P 1$ & Rare & $17 \mathrm{q} 23.2$ & 130 & Levitus et al. 2005 \\
\hline $\mathrm{L}$ & FANCL & Rare & $2 \mathrm{p} 16$ & 52 & Meetei et al. 2003a \\
\hline M & FANCM & Rare & $14 \mathrm{q} 21.2$ & 250 & Meetei et al. 2005 \\
\hline
\end{tabular}

8 of the 11 identified FA proteins (A, B, C, E, F, G, L, M). The putative catalytic element of this multisubunit complex is the L protein. The L subunit contains a PHD domain, and has homology to other E3 ubiquitin ligases (Meetei et al. 2003a). Complex 1 is required for the monoubiquitination of FANCD2 on Lys 561 during S phase of the normal cell cycle. Complex 1 is also essential for the inducible monoubiquitination of FANCD2 following cellular exposure to DNA damaging agents, such as MMC, ultraviolet (UV), or ionizing radiation (IR) and deoxynucleotide depletion due to hydroxyurea (Garcia-Higuera et al. 2001; Gregory et al. 2003). Following monoubiquitination, FANCD2 relocalizes from a soluble nuclear compartment to the chromatin fraction (Wang et al. 2004) where it colocalizes in nuclear foci with other DNA damage response proteins, including FANCD1/BRCA2 (Hussain et al. 2004; Wang et al. 2004) BRCA1 (Garcia-Higuera et al. 2001), RAD51 (Taniguchi et al. 2002a; Hussain et al. 2004), Proliferating Cell Nuclear Antigen (PCNA) (Hussain et al. 2004), and Nijmegen Breakage Syndrome (NBS1) (Nakanishi et al. 2002). Following relocalization to chromatin, monoubiquinated FANCD2 (FANCD2-Ub) promotes chromatin loading of the FANCD1/BRCA2 protein, forming a second complex (complex 2), where it may facilitate the formation of nuclear foci containing the homologous recombination (HR) DNA repair protein RAD51 (Wang et al. 2004). FA cells that fail to form either complex 1 or complex 2 are hypersensitive to cross-linking agents such as MMC and exhibit the characteristic broken and radial chromosome forms of FA.

\section{Recently identified components of the FA pathway}

Three additional FA pathway components have recently been reported. Traditional approaches, based on complementation studies of cells derived from FA patients, have identified the groups FANCI and FANCJ (Levitus et al. 2004). Experimental approaches involving the knockout of genes in chicken and human cell lines have identified FANCM (Meetei et al. 2005; Mosedale et al. 2005). We will now consider where these new components may function within the context of the basic FA pathway.

\section{FANCI, an unknown component of complex 1 ?}

FANCI cells express the multisubunit FA complex (A) $\mathrm{B} / \mathrm{C} / \mathrm{E} / \mathrm{F} / \mathrm{G} / \mathrm{L} / \mathrm{M}$ complex), but fail to monoubiquitinate FANCD2 (Levitus et al. 2004). Accordingly, the FANCI protein may be another loosely associated protein of complex 1, such as an E2 ubiquitin conjugating protein, which is not required for complex assembly but rather is required for E3-mediated monoubiquitination of FANCD2. To date, however, the FANCI gene has not been cloned.

\section{FANCM is the mammalian ortholog of Hef}

Very recently, two groups have identified the human ortholog of helicase-associated endonuclease for forked structured DNA (Hef) as a component of FA complex 1. Hef was originally described in archaebacteria as a protein that could process blocked DNA replication forks into double-strand DNA breaks (Komori et al. 2002). Meetei et al. (2005) identified the human ortholog of Hef as a $250-\mathrm{kDa}$ component of complex 1 using coimmunoprecipitation experiments. Small interfering RNA (siRNA)-mediated depletion of this protein in HeLa cells resulted in a failure to monoubiquitinate FANCD2, confirming a functional role in complex 1. Genotyping of an individual with previously unclassified Fanconi Anemia identified a nonsense mutation in the Hef gene on one allele and a partial deletion of the gene on the other. They concluded that mutation in Hef represents a new FA complementation group, FANCM. However, it is important to note that FA-M cells have not yet been complemented with a wild-type FANCM gene construct. This may be due to difficulty in ectopically expressing the 250-kDa protein (Meetei et al. 2005).

In a separate study, Mosedale et al. (2005) used knockout studies to characterize the function of the Hef ortholog in DT40 chicken cells. They noted that Hef-knockout 
cells are highly sensitive to MMC and demonstrate chromosomal instability. When Hef was knocked out of FANCC disrupted cells, no further sensitivity was noted, indicating that Hef functions within the FA pathway. Consistent with this hypothesis, Hef coimmunoprecipitated with labeled FANCF and FANCC, suggesting that it is a component of complex 1. Furthermore, Hef was required for the relocalization of complex 1 to chromatin following DNA damage. They also noted that Hef was required for DNA damage-induced FANCD2 monoubiquitination, indicating that it has a role in the monoubiquitin ligase activity of complex 1 (Mosedale et al. 2005). Interestingly, the FANCM-deficient DT40 cells were defective in the HR mediated repair of DNA cross-links due to MMC but demonstrated normal HR repair of double-strand breaks (DSBs). This observation suggests some specificity for the FA pathway in the processing of DNA cross-links as opposed to other forms of DNA damage and could explain the specific high sensitivity to cross-linking agents seen in cell lines derived from FA patients.

In bacterial cells, Hef has both endonuclease and helicase domains that function together to unwind and cleave synthetic complexes that mimic stalled replication forks (Komori et al. 2002). Similarly, the N-terminal region of human FANCM is homologous to the DEAHbox ATP-dependent helicase family, whereas the C terminus is homologous to the endonuclease region of the nucleotide excision repair protein ERCC4. In contrast to bacterial Hef, the endonuclease domain of FANCM appears to be degenerate and nonfunctional (Meetei et al. 2005). Indeed, mutation of the endonuclease domain of FANCM in DT40 cells does not markedly affect crosslinker sensitivity (Mosedale et al. 2005). However, FANCM does demonstrate an in vitro DNA-dependent ATPase function with an affinity for single-strand and forked structures that is lost when the helicase domain is mutated (Meetei et al. 2005; Mosedale et al. 2005). Mutation of the helicase domain also results in marked cisplatin sensitivity in DT40 cells. Importantly, no in vitro helicase activity has been demonstrated for FANCM. Rather, FANCM has been shown to function as a DNA translocase in an in vitro triple-helix displacement assay (Meetei et al. 2005). This observation supports a model where FANCM moves the FA complex along DNA, perhaps in association with a replication fork. FANCM may be specifically involved in the detection of a cross-link at a stalled replication fork and may then respond by activating the rest of the FA pathway. From the recent studies it appears that FANCM function may be ATP dependent, and it would be interesting in the future to investigate if mutation of the ATPase region of this protein affects the chromatin association of complex 1 and monoubiquitination of FANCD2 following DNA cross-linker treatment.

\section{FANCJ is the DNA helicase BRIP1}

Three groups have recently reported that FANCJ is the BRCA1-Interacting Protein C-terminal helicase BRIP1 (also known as BACH1). Interestingly, in common with BRCA1 and FANCD1/BRCA2, heterozygous mutation of $B R I P 1$ predisposes to early onset breast cancer, further supporting a role for the FA pathway in breast cancer development (Cantor et al. 2001).

Levitus et al. (2005) used positional cloning and a microcell-mediated chromosome complementation approach to study eight cell lines derived from FA-J individuals. They identified eight different mutations affecting the helicase domain of BRIP1, of which five were predicted to result in a protein truncation and the remainder a full-length protein with an altered amino acid residue. Three patients were homozygous for the same mutation whereas five carried a different mutation on each allele. Complementation of FANCJ mutant cells was achieved using part of chromosome 17 but not specifically with expression of a wild-type BRIP1 gene or cDNA construct.

Similarly, Levran et al. (2005) used genetic mapping to initially study 5 patients assigned to complementation group FA-J and then a further 18 unclassified FA patients. They also identified homozygous mutations in the BRIP1 gene in FA-J patients and reported an additional two truncating mutations, an insertion mutation and a missense mutation predicted to disrupt the helicase domain of the BRIP1 protein.

Two other groups also recently identified BRIP1 as FANCJ by using knockout approaches in cell lines. Litman et al. (2005) used siRNA to silence BRIP1 expression in MCF7 human breast cancer cells whereas Bridge et al. (2005) used a BRIP1 knockout approach in chicken DT40 cells. Both studies reported that abrogation of BRIP1 expression resulted in a FA cellular phenotype with profound cross-linker sensitivity and an accumulation in the G2/M phase of the cell cycle following DNA damage. Litman et al. also demonstrated a truncating mutation of BRIP1 in the FA-J AG656 cell line and showed that lentiviral-mediated expression of BRIP1 in this cell line corrected the G2/M cell cycle abnormality. Interestingly these papers reported differing results as regards the role for BRIP1 in HR. Litman et al. found a defect in the HR of a I-Scel induced DSB in the BRIP1deficient MCF7 cells whereas Bridge et al. reported normal repair of the same lesion in the BRIP1-deficient DT40 cells. The reason for these differing results is unclear but may relate to differences between human and chicken cells. Indeed, chicken BRIP1 is structurally different from its human counterpart. It is only $54 \%$ homologous to human BRIP1 and does not contain the BRCT-binding consensus sequence (Bridge et al. 2005). This sequence appears to be required for the response to DNA damage in mammalian cells by mediating an association with BRCA1 (Yu et al. 2003).

Although the function of BRIP1 is unclear, it seems likely that it has a role in the processing of intermediate DNA structures during repair. BRIP1, in common with Bloom helicase (BLM), is a member of the recQ DEAH helicase family. However, BLM in contrast to BRIP1 has been reported to suppress sister chromatid exchange (SCE) in HR (Onclercq-Delic et al. 2003). BRIP1 demon- 
strates an in vitro $5^{\prime}-3^{\prime}$ DNA unwinding activity of forked DNA duplexes whereas BLM demonstrates a 3'5' helicase activity (Karow et al. 1997; Gupta et al. 2005). BRIP1, in common with BLM, also associates with DNA substrates mimicking Holliday Junctions (Litman et al. 2005) although, in contrast to BLM, no unwinding of these structures has been demonstrated (Gupta et al. 2005). Therefore, it has been hypothesized that BRIP1 may promote HR by blocking the access of BLM to intermediate DNA structures or by providing a scaffold for other HR proteins (Litman et al. 2005). Although the role for $\mathrm{BACH}$-associated helicase activity remains unclear, its importance is demonstrated by the observation that disease-related mutations all disrupt the helicase domain (Levitus et al. 2005; Levran et al. 2005). Moreover, specific mutation of the helicase domain of BRIP1 in chicken DT40 cells results in hypersensitivity to cisplatin (Bridge et al. 2005).

Another question that both these papers raise is the role of BRCA1 in the FA pathway. BRIP1 is phosphorylated and associates with the BRCA1 C Terminus (BRCT) motifs of BRCA1 during $S$ phase of the cell cycle (Rodriguez et al. 2003; Yu et al. 2003). The association between BRCA1 and BRIP1 has been reported to be essential for DNA repair and cell cycle checkpoint functions following radiation-mediated DNA damage (Cantor et al. 2001; Yu et al. 2003). However, Litman et al. (2005) reported that BRIP1 was not required for RAD51 foci formation after hydroxyurea treatment whereas BRCA1 was essential, indicating that these proteins may have some distinct functions. Bridge et al. (2005) also reported that BRIP1 functioned independently of BRCA1 in the DT40 cell line. One possible explanation for these discrepancies is that the role of BRIP1 in the response to replication fork arrest is distinct from that in radiation damage repair and independent of BRCA1. Indeed, BRIP1 knockout DT40 cells are not very sensitive to radiation damage but are hypersensitive to cross-linking agents (Bridge et al. 2005). It is also important to note that the chicken ortholog of BRCA1 may not function identically to the human counterpart. Chicken BRCA1 protein is only $33 \%$ homologous to human BRCA1 (Orelli et al. 2001). Abrogation of chicken BRCA1 does not result in hypersensitivity to cisplatin or to radiation damage (Bridge et al. 2005) unlike mammalian BRCA1 in which loss of function has been reported to result in marked sensitivity to both forms of DNA damage (Xia and Powell 2002; Quinn et al. 2003; Kennedy et al. 2004). Moreover, the observations that functional BRCA1 is required for DNA damage-induced FANCD2 foci (Garcia-Higuera et al. 2001) and that loss of BRCA1 function results in marked cross-linker sensitivity, chromosomal breakage, and a defect in HR (Moynahan et al. 2001a) further support a model in which $B R C A 1$, in common with BRIP1, has a role in the FA pathway.

At present the role of BRIP1 in the FA pathway is uncertain. FA-J cells, in common with FA-D1 (BRCA2 mutant) cells, express an intact FA complex 1 and exhibit normal to elevated levels of FANCD2-Ub (Levitus et al. 2004; Litman et al. 2005). These observations suggest that BRIP1 functions independently or downstream of FANCD2, perhaps as another subunit of the FANCD2-Ub/BRCA2 chromatin complex (complex 2 in Fig. 1). It is clear that future studies are required to elucidate the role of BRIP1 in the HR of DNA cross-linking lesions and answer if there is a requirement for the interaction with BRCA1. It is also important to note that no study to date has reported the correction of chromosomal breakage in FA-J cells through the exogenous expression of wild-type BRIP1. The generation of isogenic mutant and fully corrected cell lines would be expected to help answer many of the questions about the role of $B R I P 1$ in the FA pathway.

\section{The structure of the FA complex 1}

At least eight of the FA proteins (subunits A, B, C, E, F, G, L, M) interact in a large nuclear complex. This complex is shown schematically in Figure 2. While no crystal structures are available for subunits of the complex, several interactions are evident from yeast two-hybrid and coimmunoprecipitation studies.
Figure 1. Schematic interaction of the $\mathrm{FA}$ pathway. Protein complex 1 contains the A, B, C, E, F, G, L, M, and possibly I subunits. Protein complex 2 contains FANCD2-Ub, BRCA2, and possibly FANCJ. During $S$ phase, when a replication fork encounters a DNA cross-link, the FA complex (complex 1) is activated. This activation leads to the monoubiquitinaiton of FANCD2, which is then targeted to chromatin containing the cross-link. FANCD2-Ub then interacts with BRCA2 in complex 2, leading to repair of the cross-link possibly through HR and TLS. FANCD2 is deubiquitinated by USP1, thereby inactivating the pathway.

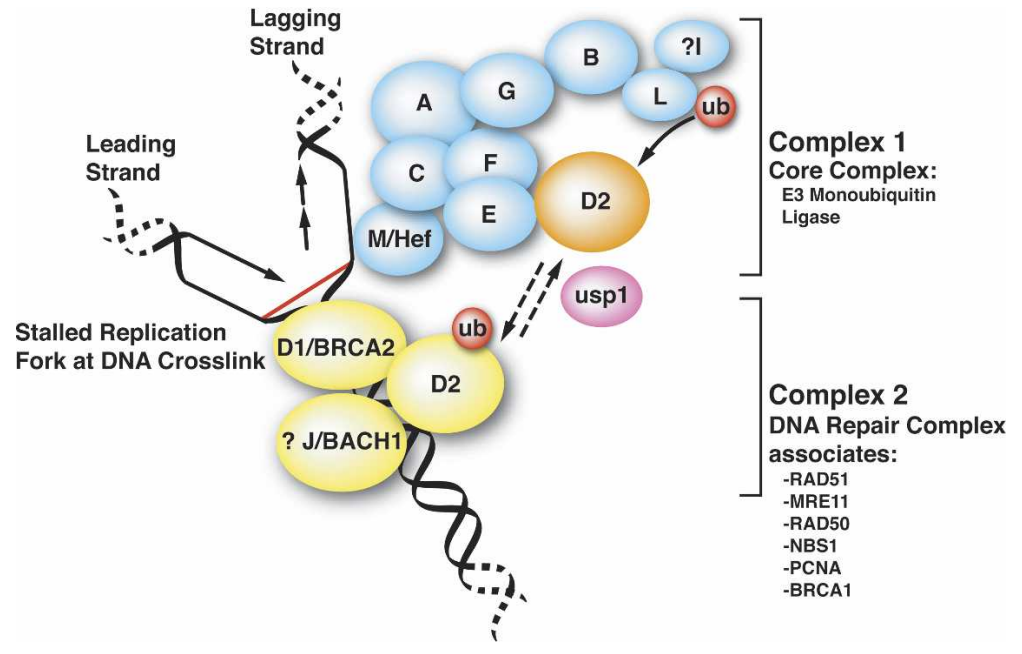




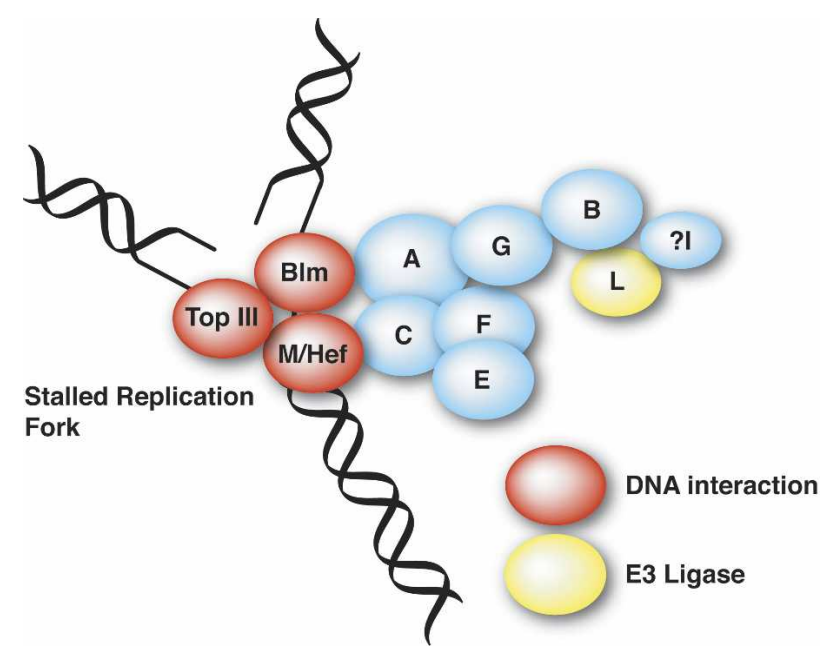

Figure 2. Schematic structure of the Fanconi Anemia E3 ligase complex (complex 1). The core complex contains subunits A, B, C, E, F, G, L, M, and possibly I. According to this model, ubiquitin is transferred from an E1 to an E2 (unknown for the FA complex) to FANCD2. The FANCD2 substrate may have direct binding interactions with FANCL and FANCE, and these interactions may be mediated, at least in part, by ATR-dependent phosphorylations on the FANCD2 protein. Importantly, recent studies indicate that complex 1 is associated with chromatin and may function as a sensor of DNA damage as well as an E3 ligase.

The FANCA and FANCG subunits interact directly, and these subunits are dependent on each other for stability. Absence of the FANCA protein shortens the halflife of the FANCG protein (Garcia-Higuera et al. 2000). Molecular studies support interactions between FANCG and FANCF (Garcia-Higuera et al. 2000), between FANCE and FANCC (Pace et al. 2002; Taniguchi and D'Andrea 2002), and between FANCB and FANCL subunits (Meetei et al. 2004). The FANCE protein is required for the efficient transport of the FANCC protein to the nucleus (Pace et al. 2002; Taniguchi and D'Andrea 2002). Interestingly, yeast two-hybrid studies have also indicated that the $\mathrm{N}$ terminus of FANCE interacts directly with FANCD2 (Gordon and Buchwald 2003), implying that complex 1 may associate with FANCD2 through FANCE, thereby facilitating FANCD2 monoubiquitination. The newly cloned FANCM, in common with other FA proteins, has been shown to be required for the stability of complex 1 and coimmunoprecipitates with FANCC and FANCF, although a direct interaction with these proteins has not been shown (Meetei et al. 2005; Mosedale et al. 2005).

Coimmunoprecipitation experiments support the presence of subcomplexes (for example, the FANCA/ FANCG and FANCE/FANCF/FANCG/FANCC subcomplexes), which may preform and translocate intracellularly before the assembly of the complete complex. Specific domains of these subunits are likely to play a role in subunit assembly, such as the tetratricopeptide repeat (TPR) domains of the FANCG subunit (de Winter et al. 1998) and the WD40 domains of the FANCL sub- unit (Meetei et al. 2003a). Phosphorylation of some of the FA subunits also appears to contribute to complex 1 assembly (Kupfer et al. 1999).

The FANCL protein has a C-terminal RING-fingerlike plant domain (PHD), believed to be directly involved in the catalytic activity of the complex. The PHD domain may interact directly with an E2 protein of the FA pathway. Interestingly, a truncated form of FANCL, lacking the C-terminal PHD domain, still binds and stabilizes the FA complex, through its three WD40 domains, but does not complement the FANCD2 monoubiquitination defect in FANCL cells (A. Gurtan and A.D. D'Andrea, unpubl.). WD40 domains of FANCL may be required for its interaction with phosphorylated residues on other FA complex subunits or perhaps with phosphorylated residues on the FANCD2 substrate. It has previously been reported that the WD40 domains of other E3 ligases are important in recruiting specific substrates to the ligase complex for ubiquitination (Orlicky et al. 2003).

While the FA complex is the putative E3 ligase for FANCD2, the in vitro reconstitution of this ligase reaction has not been successful to date. In fact, the only E3 ligase that has been demonstrated to monoubiquitinate FANCD2 in vitro is the BRCA1/BARD1 complex (Vandenberg et al. 2003). Additional subunits of the FA complex, such as the putative FANCI protein, may be required for reconstitution of the FANCL E3 ligase activity in vitro. However, the FANCL subunit does undergo autoubiquitination in vitro, and its PHD domain is required for this activity (Meetei et al. 2003a).

As will be discussed later, Bloom DNA helicase and topoisomerase III have also been reported to associate with complex 1, which, along with recent identification of FANCM as a DNA helicase, suggests that this complex has a direct role in DNA processing as well as having a monoubiquitin E3 ligase activity.

In conclusion, complex 1 has an E3 ubiquitin ligase activity directed toward FANCD2 and a DNA processing activity of uncertain purpose. Important questions remain about complex 1. First, is complex 1 associated with the advancing replication fork and does it bind to helix-distorting lesions, thereby acting as a sensor of damage? Second, do other specific subunits of complex 1, in addition to FANCM, bind directly to DNA? Third, while direct interactions among the subunits of complex have been defined by coimmunoprecipitation and yeast two-hybrid experiments, what are the precise crystallographic interactions?

\section{The structure of FA complex 2}

The downstream function of the FA pathway is largely unknown. Accumulating evidence suggests a major function of complex 1 is to generate monoubiquitinated FANCD2 (FANCD2-Ub), required for the assembly of the FANCD2-Ub/BRCA2 chromatin complex (complex 2). Following monoubiquitination, FANCD2 relocalizes to DNA damage-induced S-phase foci where it associates with the DNA repair proteins BRCA2/FANCD1 (Wang 
et al. 2004), BRCA1 (Garcia-Higuera et al. 2001), NBS1 (Nakanishi et al. 2002), RAD51 (Hussain et al. 2004), and PCNA (Howlett et al. 2005). The formation of these DNA damage-induced FANCD2 foci is dependent on the presence of functional BRCA1 (Garcia-Higuera et al. 2001), thereby linking this DNA repair protein to the FA pathway. As discussed earlier, BRIP1 (FANCJ) mutant cells demonstrate normal FANCD2 monoubiquitination, indicating that it does not form part of complex 1. Furthermore, BRIP1, in common with FANCD2, localizes to DNA damage-induced nuclear foci along with BRCA1 (Cantor et al. 2001), suggesting that it may function as part of complex 2. A diagrammatic representation of FA complex 2 is shown in Figure 1.

Perhaps the simplest model proposes that FA complex 2 contributes to the stabilization of a stalled DNA replication fork. Indeed BRCA2 (FANCD1) has been demonstrated to be required for the stabilization of the stalled replication fork following treatment with hydroxyurea (Lomonosov et al. 2003). By stabilizing the fork, the complex may facilitate DNA repair, and may be required for the recruitment of repair proteins. Accordingly, it will be interesting to determine whether disruptions of FANCD2 or BRIP1/FANCJ also result in destabilization of the replication fork.

In conclusion, complex 2 may contain a helicase activity (BRIP1) and appears to play a more downstream role in DNA repair. Important data about this complex still remain to be elucidated. First, as will be discussed further later, current data indicate that the FA pathway interacts with the process of HR repair and translesion synthesis (TLS) (Niedzwiedz et al. 2004). How complex 2 engages in these two processes remains unclear. Second, whether complex 2 has a direct function in cell cycle checkpoint activation remains unknown. Third, the molecular interactions among the protein subunits of complex 2 remain to be elucidated. Finally, it is not clear whether BRCA1 and its associated E3 ubiquitin ligase activity also play a role in the function of this complex.

\section{Activation of the FA pathway}

Now that we have described the components of the basic FA pathway, we will address how the pathway is activated following DNA damage. Several findings indicate that the Fanconi pathway is activated and functions primarily in the S phase of the cell cycle. First, cell cycle synchronization studies reveal that FANCD2 monoubiquitination occurs predominantly in S phase. FANCD2 is monoubiquitinated at the G1/S boundary, remains monoubiquitinated throughout $S$ phase, and becomes deubiquitinated at the end of $S$ phase as the synchronized cell population enters G2 (Taniguchi et al. 2002a). Second, during $\mathrm{S}$ phase, monoubiquitinated FANCD2 protein specifically colocalizes with replication foci containing BRCA1, RAD51 (Taniguchi et al. 2002a; Hussain et al. 2004), and PCNA proteins (Howlett et al. 2005). These foci are believed to represent sites of homologous repair. Third, the FA complex 1 associates with chromatin during $\mathrm{S}$ phase, and is released in mitosis ( $\mathrm{Mi}$ and Kupfer 2005).

Recent studies indicate that the FA pathway is activated during $S$ phase in response to DNA replication fork arrest. Replication fork arrest leads to the local generation of single-strand DNA, perhaps through helicase unwinding of the DNA duplex. Single-strand DNA binds RPA (Replication Protein A) and then ATR (Ataxia Telangiectasia and RAD3-related protein) and ATRIP (ATRInteracting Protein). After recruitment to the stalled fork, ATR phosphorylates multiple substrates, leading to additional cell cycle checkpoint and DNA repair responses (Zou and Elledge 2003). One principal substrate of ATR is CHK1 (Checkpoint Kinase 1). Recent studies implicate ATR/CHK1 in the activation of the FA pathway. First, agents that activate ATR kinase, such as hydroxyurea, cross-linkers, or ultraviolet light are potent activators of FANCD2 monoubiquitination (Gregory et al. 2003). Second, cells from patients with Seckel syndrome express a mutant ATR and fail to monoubiquitinate FANCD2 following DNA damage. Similarly, siRNA-mediated silencing of ATR expression abrogates FANCD2 monoubiquitination (Andreassen et al. 2004). Third, knockdown of ATR also results in a chromosome breakage phenotype and cellular hypersensitivity to MMC, consistent with an upstream role for ATR in the FA pathway (Andreassen et al. 2004). Moreover, disruption of the CHK1 kinase either by siRNA knockdown or by specific inhibitors of CHK1 kinase leads to DNA cross-linker sensitivity and a disruption of the FA pathway (X. Wang and A.D. D'Andrea, unpubl.). Fourth, the recently identified FANCM protein is hyperphosphorylated following DNA damage. This protein has multiple ATR consensus sites, although the ATR-mediated phosphorylation of these sites have yet to be investigated (Meetei et al. 2005).

Taken together, these results support a model in which ATR and CHK1, in response to DNA replication fork stalling, modulate the FA pathway. This may occur through the direct phosphorylation of one or more subunits of complex 1. For example, phosphorylation of FANCM may promote the DNA translocation of complex 1 and facilitate the identification of DNA crosslinks, leading to subsequent activation of the rest of the FA pathway, which in turn may be involved in the processing of the lesion that has given rise to the failure in DNA replication.

\section{Functions of the FA pathway}

Despite extensive research into this area, the specific functions of the FA pathway following activation by DNA replication fork arrest are uncertain. However, recent studies suggest that it may function to coordinate several aspects of DNA damage response including (1) direct enzymatic DNA processing, (2) recruitment of DNA repair proteins involved in HR and TLS, and (3) cell cycle checkpoint activation (Fig. 3). 


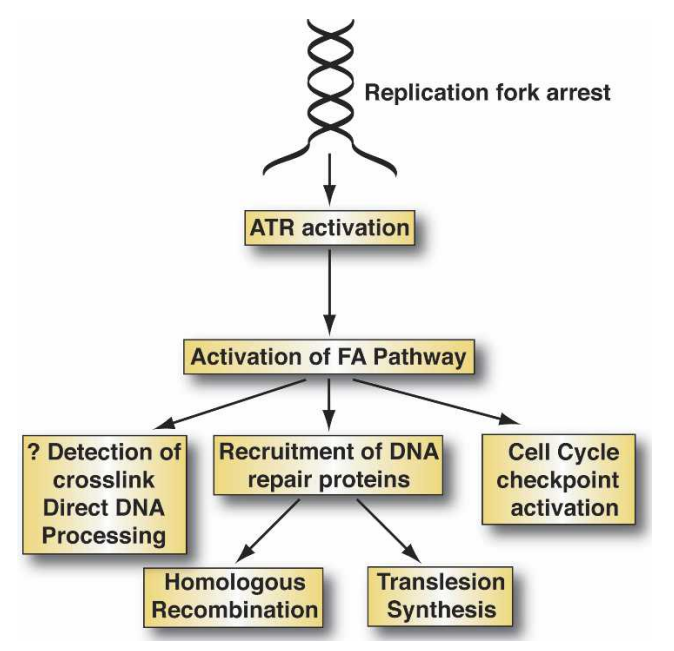

Figure 3. A schematic diagram depicting how the FA pathway may function to coordinate the cellular response to replication fork arrest following DNA damage. ATR is activated in response to replication fork arrest and in turn may activate the FA pathway, which detects the DNA lesion and coordinates its repair.

\section{Enzymatic DNA processing}

As discussed earlier, the most recently identified FA proteins (J and $\mathrm{M}$ ) have DNA helicase domains (Levitus et al. 2005; Meetei et al. 2005). BLM and topoisomerase III have also been found to associate with FA complex 1 (Meetei et al. 2003b). BLM, topoisomerase III, and replication protein A associate with constituents of the FA complex 1 (the BRAFT complex) (Meetei et al. 2003b). These proteins have been shown to cooperate in DNA unwinding and have been implicated in the response to replication fork arrest (Chan et al. 1987; Brosh Jr. et al. 2000; Wu and Hickson 2002). Mutation of BLM in common with other FA genes results in chromosomal breakage (Risinger and Groden 2004), although it is important to note that $B L M$-deficient cells also exhibit increased SCE, a phenotype not observed in FA cells.

FA complex 2 colocalizes with NBS1, a component of the MRE11/RAD50/NBS1 (MRN) complex that has 3'-to-5' exonuclease activity and is required for DNA processing prior to repair through HR (Nakanishi et al. 2002; Kobayashi et al. 2004). Loss of function of the FA pathway has been associated with a failure of the MRN complex to form at sites of DNA damage (Pichierri et al. 2002).

Overall, these observations linking the FA pathway to DNA processing suggest that the FA proteins not only function in DNA damage signaling pathway but may also have active roles in the detection and processing of stalled replication forks. Consequently, loss of the FA pathway may lead to chromosomal instability through the failure to process DNA repair intermediates.

\section{Recruitment of DNA repair proteins}

Homologous recombination (HR) HR is a process by which double-strand DNA breaks are repaired through the alignment of homologous sequences of DNA and occurs primarily during the late $S$ to $M$ phase of the cell cycle. This repair pathway requires the $3^{\prime}-5^{\prime}$ exonuclease activity of the RAD50, MRE11, and NBS1 complex to expose the $3^{\prime}$ ends on either side of the DSB, a process that may also require BRCA1 (Zhong et al. 1999). The break can then be repaired by one of two main pathways. Either single-strand annealing, a potentially mutagenic process that uses regions of homology between the complementary strands to align the broken ends of DNA, or strand invasion, a RAD51- and BRCA2-dependent process that typically uses either a homologous sequence in adjacent DNA or the sister chromatid as a template to repair the break. This latter process may result in a SCE of genetic material (Wyman et al. 2004).

During $S$ phase, DNA cross-links result in a replication fork arrest. In the process of repair, the cross-links are excised by an endonuclease leading to the generation of DSB intermediates (Dronkert and Kanaar 2001; Rothfuss and Grompe 2004). The DSB can then be repaired by HR. Following treatment with cross-linkers, DSB formation has been reported to precede FANCD2 monoubiquitination. FANCD2-Ub then colocalizes with Histone 2AX S-phase foci, a marker of DSBs, indicating a role for the FA pathway in the repair of this type of DNA damage. Accordingly, disruption of the FA pathway results in persistence of DNA breakage (Rothfuss and Grompe 2004). It is interesting to note that although XPF/ERCC1 has been reported to colocalize with FANCA, suggesting it may function in the FA pathway (Sridharan et al. 2003), XPF/ERCC1 mutant cells demonstrate normal FANCD2 monoubiquitination (R.D. Kennedy and A.D. D'Andrea, unpubl.). This implies that another endonuclease such as the Mus81-Eme1 complex (Abraham et al. 2003) is, at least partly, involved in the excision of DNA cross-links upstream in the FA pathway.

Monoubiquitinated FANCD2 associates with BRCA1 (Garcia-Higuera et al. 2001), BRCA2 (Hussain et al. 2004; Wang et al. 2004), RAD51 (Hussain et al. 2004), PCNA (Howlett et al. 2005), and NBS1 (Nakanishi et al. 2002) and is required for the relocalization of BRCA2 to chromatin and the subsequent formation of RAD51 foci (Hussain et al. 2004; Wang et al. 2004). Although the purpose of FANCD2 monoubiquitination remains unknown, it seems likely that it has a role in HR as BRCA1, BRCA2, RAD51, and NBS1 have all been implicated in this process (Moynahan et al. 1999; Tutt et al. 2001; Kobayashi et al. 2004). In support of this hypothesis, cell lines deficient in the FA pathway have been reported to have defective HR (Donahue et al. 2003; Yamamoto et al. 2003; Niedzwiedz et al. 2004; Nakanishi et al. 2005). In general, disruption of upstream FA proteins, such as FANCA (Nakanishi et al. 2005) and FANCG (Yamamoto et al. 2003) result in milder HR defects than disruption of BRCA2/FANCD1 (Moynahan et al. 2001b), suggesting that the FA chromatin-associated complex 2 is largely responsible for the DNA repair functions of the FA pathway. Interestingly, recent evidence suggests that DNA cross-links may be preferentially repaired by the singlestrand annealing subset of HR (Jonnalagadda et al. 2005). 
Murine cells deficient in components of complex 1 or FANCD2 demonstrate abnormal single-strand annealing following cross-linker damage, suggesting a specific role for the FA pathway in this subset of HR (Nakanishi et al. 2005; Yang et al. 2005).

Translesion synthesis (TLS) Another proposed role for the FA pathway is TLS. This process can result in point mutations due to the misincorporation of nucleotides. TLS may offer an alternative to HR in order to re-establish replication forks or may work in conjunction with $\mathrm{HR}$ in the resolution of certain types of DNA damage (Niedzwiedz et al. 2004). The best characterized DNA damage resulting in TLS is the ultraviolet-induced cyclobutane pyrimidine dimer (CPD), although TLS is also likely to bypass DNA adducts such as those produced by cross-linking agents (Yamashita et al. 2002). CPD damage is either repaired by nucleotide excision repair (NER) or bypassed by TLS (Friedberg et al. 2002; Prakash and Prakash 2002). At the beginning of the process of TLS, a normal replicative DNA polymerase, such as Pol $\delta$, encounters a CPD and is displaced by a TLS polymerase (Friedberg et al. 2005). The TLS polymerase can replicate past CPD damage with higher fidelity and efficiency than a replicative polymerase (Yu et al. 2001). Evidence for the role of the FA pathway in TLS comes from experiments in the DT40 chicken cell line where loss of the TLS proteins Rev1 and Rev3 along with FANCC are epistatic as regards DNA cross-linker sensitivity. Rev1 and monoubiquitinated FANCD2 are also observed to colocalize in nuclear foci following replication fork arrest (Niedzwiedz et al. 2004). Loss of the FA pathway results in a hypomutable phenotype following crosslinker treatment, further suggesting a relationship between the FA and TLS pathway (Papadopoulo et al. 1990a,b). Furthermore, Rev1 deficient DT40 cells, in common with FA cells, demonstrate hypersensitivity to cisplatin (Ross et al. 2005). Finally, as will be discussed later, recent evidence suggests that the FA pathway and TLS are terminated by the same deubiquitinating enzyme, USP1, further indicating their coordinate regulation (T. Huang and A.D. D'Andrea, unpubl.).

One hypothesis, which may link the HR and TLS functions of the FA pathway, is the requirement for both processes in the repair of DNA cross-links. These lesions are unusual in that they require the excision of adducts on both strands of DNA and the subsequent repair of the resultant DSB in $S$ phase (Rothfuss and Grompe 2004). The FA pathway may function to coordinate the excision and bypass of DNA adducts with the HR of DSBs. Consistent with this model, components of the FA pathway, HR, and TLS have all been shown to be required for the repair of cross-links in chicken DT40 cells (Niedzwiedz et al. 2004). Figure 4 demonstrates a simplified version of the model recently proposed by Niedzwiedz et al.

Niedzwiedz et al. (2004) also reported some interesting data regarding the role of the FA pathway and TLS in the response to endogenous DNA damage. Unlike cross-link repair, in which TLS and HR appear to cooperate, the FA pathway promotes either HR or TLS independently in the repair of abasic sites (Niedzwiedz et al. 2004). Therefore, loss of the FA pathway may be predicted to result in a failure to repair endogenous DNA damage efficiently, thereby promoting chromosomal instability.

In contrast to the Rev1 and Rev3 knockout studies, Rad18, another TLS protein, has been reported to function independently of FANCC in DT40 cells. The Rad6/ Rad18 complex mediates PCNA monoubiquitination, thereby facilitating recruitment of a TLS polymerase. The combination of Rad18 and FANCC knockout results in greater cisplatin sensitivity than either knocked
Figure 4. A simplified model of FA-mediated crosslink repair that involves NER, TLS, and HR. (1) The replication fork arrests at a DNA cross-link and is detected by FA complex 1. FA complex stabilizes the arrested fork. (2) NER excises one side of the cross-link leaving a single-strand DNA break on one strand and a monoadduct on the opposite strand. (3) FA recruits TLS to bypass the remaining monoadduct. (4) NER excises the monoadduct. (5) FA-mediated HR of double-strand DNA break. (6) Intermediate DNA crossover structures are resolved and the replication fork is re-established, a process that may require FA pathway-associated DNA helicases.

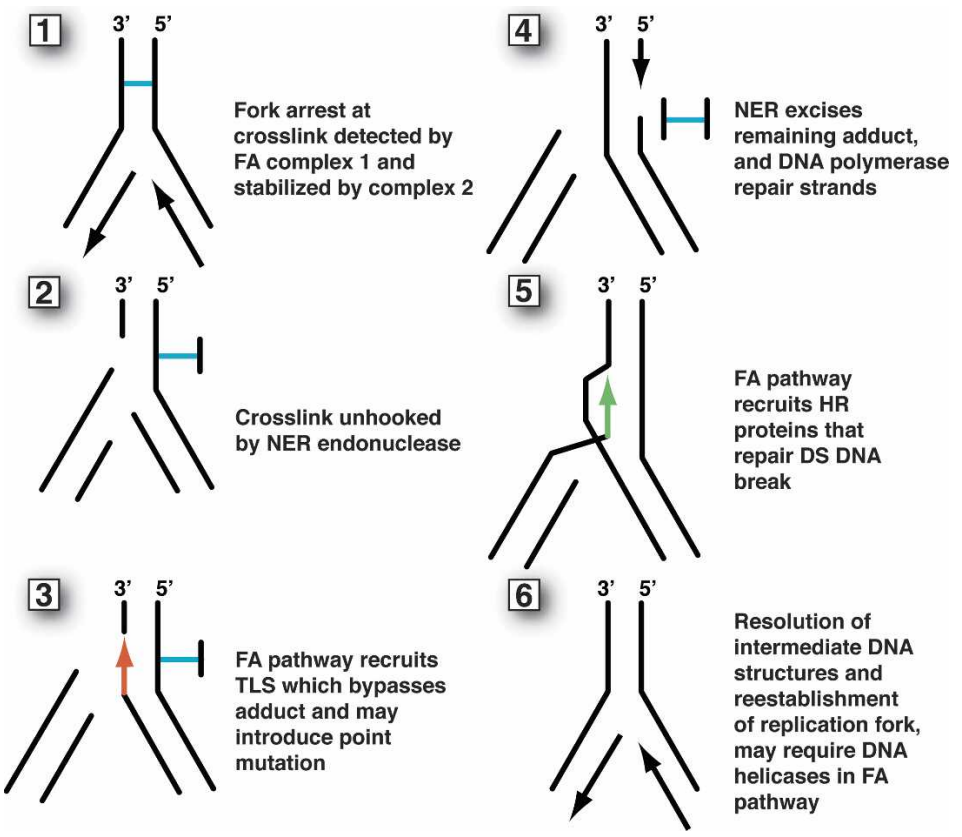


out independently (Hirano et al. 2005). These data suggest that FA pathway-mediated TLS may be Rad18 independent. Indeed, Rad18-independent TLS has been reported in vertebrate cells (Okada et al. 2002).

\section{Cell cycle regulation}

FA cells characteristically demonstrate an accumulation of 4N DNA content either spontaneously or following treatment with DNA cross-linkers (Kubbies et al. 1985). Indeed, this consistent observation has been proposed as a diagnostic test for FA (Miglierina et al. 1991). One hypothesis to explain this phenotype has been that FA cells fail to arrest in S phase due to DNA damage and accumulate at the G2/M damage checkpoint (Centurion et al. 2000; Sala-Trepat et al. 2000). Other investigators have proposed that FA cells arrest in late $S$ phase due to a failure to remove DNA cross-links (Akkari et al. 2001). At present, the function of the FA pathway in cell cycle regulation remains uncertain, largely due to the different methodologies and cell line models used to study this question. Published evidence suggests that the FA pathway may have roles in the DNA replication, intra-Sphase, and G2/M DNA damage checkpoints.

The DNA replication checkpoint is activated during $S$ phase in response to stalled DNA replication and primarily involves the ATR-mediated phosphorylation of DNA damage response kinases such as CHK1. It functions to allow the stabilization and repair of the stalled replication fork or the restoration of a depleted deoxynucleotide pool. It also functions to stop the firing of further DNA replication origins, preventing the formation of new replication forks until the existing damage has been repaired (Bartek et al. 2004). A role for the FA pathway in the replication checkpoint is supported by the observations that FANCD2 monoubiquitination is dependent on ATR activation and that constituents of complex 1 (the E3 ligase complex) and FANCD2 have both been shown to be required for S-phase cell cycle arrest following cross-link damage /Centurion et al. 2000; Sala-Trepat et al. 2000; Pichierri and Rosselli 2004).

In addition to the replication checkpoint, there is evidence that the FA pathway may function in a second S-phase checkpoint, the intra-S-phase checkpoint. This checkpoint is predominantly activated by the ataxia-telangiectasia-mutated (ATM) kinase and the ATM substrate CHK2 in response to double-strand DNA breakage and is not dependent on replication fork arrest (Bartek et al. 2004). Cells derived from FA patients replicate DNA in the presence of radiation damage, a feature of a deficient intra-S-phase checkpoint. ATM-mediated phosphorylation of FANCD2 at Ser 222, a process that also depends on NBS1, has been shown to be required for this checkpoint.

Indeed, recent studies suggest a direct interaction between the C terminus of FANCD2 and ATM (S. Margossian and A.D. D'Andrea, unpubl.). Interestingly, activation of the intra-S-checkpoint is independent of the monoubiquitination of FANCD2 (Taniguchi et al. 2002b).
Recent data also suggest that the FA pathway has a role in maintaining the G2/M boundary DNA damage checkpoint, which exists to prevent progession into mitosis prior to the repair of abnormally replicated DNA. This checkpoint is activated by either ATM or ATR and their downstream kinase targets depending on the type of DNA damage (Liu et al. 2000; Shiloh 2001; Helt et al. 2005). Murine cells deficient in FANCC or FANCD2 undergo an abnormal progression into mitosis following DNA damage when compared with wild-type cells (Freie et al. 2004). Interestingly, loss of BRIP1 (FANCJ) function also results in a defect in the G2/M checkpoint, suggesting that this protein may function in a common pathway with the other FA proteins in G2/M checkpoint regulation (Yu et al. 2003).

\section{Turning off the FA pathway: the FANCD2 Dub}

Inappropriate activation of the FA pathway in undamaged cells may lead to harm by promoting mutagenic TLS. Consequently cells may have developed mechanisms of shutting off the pathway when it is not needed. The Deubiquitinating enzyme (Dub), USP1, has recently been identified as a critical enzyme that regulates the FA pathway. Dub enzymes are cysteine proteases that cleave peptide and isopeptide linkage immediately after the glycine-glycine sequence (i.e., the $\mathrm{C}$ terminus of ubiquitin) (D'Andrea and Pellman 1998; Wilkinson 2000; Amerik and Hochstrasser 2004).

The role of USP1 in the FA pathway was originally identified using a retroviral small hairpin RNA (shRNA) library (Nijman et al. 2005). Pools of shRNA molecules were used to abrogate the expression of specific Dub enzymes. ShRNA depletion of USP1 resulted in increased FANCD2-Ub levels, without promoting DNA damage. Moreover, USP1 activity peaks at the end of S phase, perhaps accounting for the observed deubiquitination of FANCD2 in late S phase.

Interestingly, USP1 has also recently been identified as the Dub for PCNA, and therefore has a role in downregulating TLS (T. Huang and A.D. D'Andrea, unpubl.). Loss of USP1 function results in elevation and prolongation of PCNA ubiquitination. This provides further evidence for the intertwined nature of the FA pathway and TLS. It is important to note that, unlike all the other FA proteins described in Figure 1, mutation of the USP1 protein has not yet been directly linked to the pathogenesis of FA or other human disease.

\section{Cancer risk in heterozygous carriers of FA gene mutation}

Increased cancer risk is a well-recognized clinical feature of FA and has been reviewed extensively in other articles (Alter 2003; Kutler et al. 2003b). However, more recent work has shown that although heterozygous carriers of FA gene mutations do not demonstrate developmental or bone marrow abnormalities, there is a predisposition to cancer in these individuals. In particular, studies have 
reported a strong association between heterozygous mutation of FA genes and susceptibility to breast or ovarian cancer. Carriers of mutations in BRCA1 or BRCA2/ FANCD 1 have an $82 \%$ lifetime risk of breast cancer and a $54 \%$ and $23 \%$ risk of ovarian cancer, respectively (King et al. 2003). Mutations in FANCJ (BRIP1) have also been identified in patients with early onset breast cancer (Cantor et al. 2004) although the lifetime risk is unknown. This observation suggests that the FA pathway is important in the prevention of these female cancers and that unidentified mutations of other FA genes may account for some familial breast/ovarian cancer pedigrees not accounted for by BRCA1 or BRCA2/FANCD1.

Why mutations in these components of the FA pathway specifically lead to breast and ovarian cancers is unknown. One possibility is that estrogen in some way promotes the survival of breast and ovarian cells that have undergone critical DNA damage, whereas apoptosis occurs normally in other somatic cells (Elledge and Amon 2002). Consistent with this hypothesis, oophorectomy, which diminishes serum estrogen levels, protects against breast cancer in BRCA1 and BRCA2/FANCD1 mutation carriers (Rebbeck et al. 2002).

Paradoxically, FA patients rarely develop breast or ovarian cancer. This may be because these patients are often hypogonadal. Accordingly, they have decreased estrogen levels, perhaps resulting in a decreased incidence of these hormonally related tumors. Also, in families carrying a BRCA1 or BRCA2/FANCD1 mutation, the peak age of onset of breast or ovarian cancer is in the fourth decade (Ford et al. 1994), whereas FA patients often die from complications of aplastic anemia or other cancers before this age.

In addition to breast and ovarian cancer, heterozygosity for a mutation in BRCA2/FANCD1 predisposes to pancreatic cancer. In one study $19 \%$ of families with a history of hereditary pancreatic cancer had either a frameshift mutation or an unclassified variant of BRCA2/FANCD1 (Hahn et al. 2003). Other FA gene mutations have also been identified in pancreatic cancer. One recent study determined that two out of 400 patients with pancreatic cancer carried a heterozygous germline mutation in FANCC (Couch et al. 2005). Interestingly, the pancreatic tumors from these patients exhibited loss of heterozygosity ( $\mathrm{LOH})$ at the FANCC locus, indicating that loss of FANCC function resulted from a mutation of one allele and deletion of the other, consistent with Knudson's two-hit hypothesis for tumor suppressor genes (Knudson Jr. 1971).

Other studies have identified human pancreatic tumor lines with biallelic loss of FANCC and FANCG (van der Heijden et al. 2004). These tumor lines were derived from individuals who were heterozygote at these loci. Taken together, these data indicate that heterozygote carriers, carrying one mutant FANCC or FANCG allele, may have increased pancreatic cancer risk, albeit at lower penetrance than in the case for a BRCA2/FANCD1 mutation.

Other cancers that have been reported to be associated with heterozygous mutation of a FA gene include
BRCA2/FANCD1 related prostate cancer, gastric cancer, and melanoma (Liede et al. 2004), FANCA related acute myeloid leukemia (Condie et al. 2002; Tischkowitz et al. 2004), and FANCC related acute lymphoblastic leukemia (Rischewski et al. 2000).

\section{Epigenetic disruption of the FA pathway}

The human ovarian cancer cell line, 2008, fails to monoubiquitinate FANCD2 following DNA damage. This results from methylation of the FANCF promoter and a consequent loss of FANCF protein expression. Four out of 19 primary ovarian adenocarcinomas were also demonstrated to have FANCF methylation. Interestingly, prolonged treatment of the 2008 cell line with cisplatin resulted in restoration of FANCF expression, suggesting that correction of the FA pathway may account for acquired resistance to this treatment in a clinical setting (Taniguchi et al. 2003). Recent studies have also identified methylation of the FANCF promoter in $24 \%$ of ovarian granulosa cell tumors (Dhillon et al. 2004), 30\% of cervical cancer (Narayan et al. 2004), 14\% of squamous cell head and neck cancers, and 15\% of non-small-cell lung cancers, where in the latter it correlated with a worse prognosis (Marsit et al. 2004). Epigenetic factors affecting the FA pathway may also be important for the development of sporadic acute myeloid leukemia (AML) where absent or reduced expression of the FA proteins FANCA, FANCC, FANCF, and FANCG has been reported (Xie et al. 2000). Taken together these observations imply that loss of the FA pathway is an early step in the development of some sporadic tumors or alternatively is subsequently lost in order to confer some advantage to the tumor, such as a tolerance of abnormal DNA replication.

\section{The FA pathway and cancer treatment}

The association between abnormalities in the FA pathway and cancer development may have important clinical implications as regards treatment. FA patients who are homozygous for mutation of a FA gene have a systemic DNA repair defect that results in a low tolerance for DNA-damaging chemotherapeutic agents. Accordingly chemotherapeutic agents are often given at low dosage or are avoided in favor of surgical approaches (Kutler et al. 2003a). The situation, however, is different for cancer patients who carry a heterozygous mutation in a FA gene. In this scenario the tumor contains an abnormal FA pathway and would be predicted to be more DNA damage sensitive whereas the patient's other cells, such as those in the bone marrow, contain a functional pathway and would be relatively more DNA damage resistant. Consistent with this model BRCA2/FANCD1 mutation carriers, with breast or ovarian cancer, demonstrate a high response to DNA-damaging chemotherapeutic agents (Chappuis et al. 2002; Cass et al. 2003). It remains to be seen if malignancies associated with heterozygosity for other FA gene mutations demonstrate the same level of chemosensitivity. 
Recent studies have indicated that tumor cells with a profound HR defect, such as those deficient in BRCA1 or $B R C A 2$, are highly dependent on Poly ADP Ribose Polymerase (PARP) for survival. Consequently, these tumors are hypersensitive to PARP inhibitors (Bryant et al. 2005; Farmer et al. 2005). It will be interesting to determine whether tumor cells with a disruption of the FA pathway have a comparable hypersensitivity to PARP inhibitors.

\section{Unanswered questions}

The realization that the FA pathway is intimately involved in the response to DNA damage has led to a marked growth in research in the field. Despite this increased interest, some fundamental questions still remain to be answered. In particular, it is still unknown why FA patients develop the typical syndrome of developmental abnormalities, bone marrow failure, and a predisposition to malignancy. It is also unknown why cells deficient in the FA pathway show particularly high sensitivity to cross-linking agents despite the activation of the pathway by a number of different forms of DNA damage. Here we speculate about these issues in the light of recent publications.

How do abnormalities in the FA pathway result in the FA phenotype?

Cells from FA patients have a complete disruption of the FA pathway and exhibit both spontaneous and DNA damage-inducible chromosome aberrations. Recent data implicate the tumor suppressor p53 in a mechanism that detects critical DNA damage in cells that have a disrupted FA pathway and prevents its propagation through apoptosis. When FANCD2 is knocked out of zebrafish embryos, a proportion of the cells undergo apoptosis mediated by $\mathrm{p} 53$, resulting in developmental abnormalities. SiRNA-mediated silencing of p53 in the embryo prevents this apoptotic process (Liu et al. 2003). Consistent with these observations, mice with a constitutive knockout of FANCD2 develop to adulthood but eventually form solid tumors. Deletion of one allele of p53 results in an earlier onset of malignancy, suggesting a failure of tumor surveillance (Houghtaling et al. 2005). Further evidence suggesting a role for p53 in the surveillance for critical DNA damage in FA cells comes from a study of squamous cell carcinomas in FA patients. This work has demonstrated an association with human papilloma virus (HPV) infection and the tumor development. HPV E6 protein is known to reduce p53 protein levels as part of the infective process, thereby preventing the activation of apoptotic pathways (Kutler et al. 2003c).

These observations suggest a model in which p53 is involved in preventing the malignant progression of FA cells (Fig. 5). Perhaps, when a FA cell has become critically damaged, p53 is involved in activating apoptosis, thereby preventing tumor formation. If this process were to happen in embryonic stem cells it may account for the

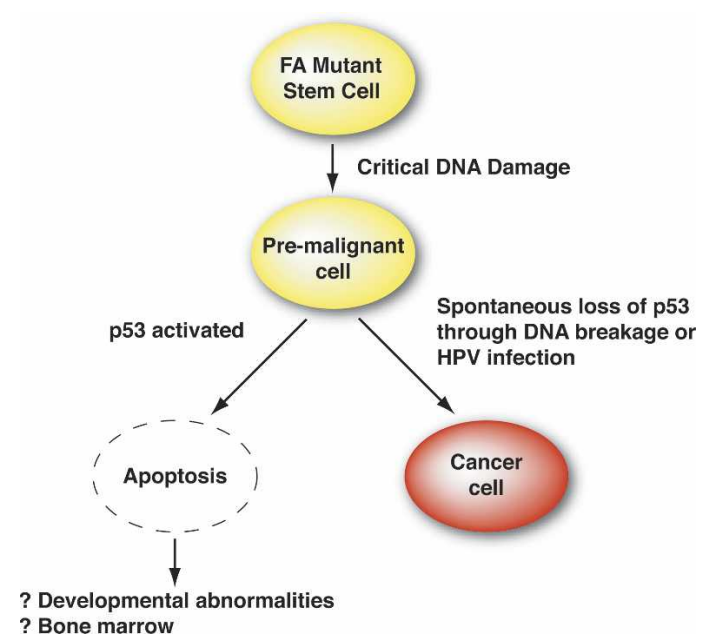

Figure 5. p53 may function to prevent the propagation of damaged DNA through apoptosis. This may lead to stem cell depletion in FA patients, causing congenital abnormalities and bone marrow failure. Loss of p53 function may predispose to cancer by allowing premalignant cells to survive.

developmental abnormalities observed. Loss of stem cells in the bone marrow may also account for the progressive anemia associated with FA. Loss of p53 or other genes involved in apoptotic function, perhaps through viral infection or FA-associated DNA breakage, may allow a cell with critical DNA damage to survive, resulting in cancer.

Why are FA cell lines specifically hypersensitive to cross-linking agents?

The FA pathway is activated by many types of genotoxic stress, including UV light, ionizing radiation, hydroxyurea, and cross-linking agents (MMC, CDDP, DEB). Surprisingly, despite the broad array of activators, FA cells are primarily hypersensitive only to cross-linking agents (Duckworth-Rysiecki and Taylor 1985; Carreau et al. 1999|. What is the basis of this cross-linker specificity? Using bacterial assays, it has been reported that a single persistent DNA cross-link is enough to prevent DNA replication and cause cell death (Lawley and Phillips 1996). Given the lethality of this lesion, one hypothesis is that the FA pathway is activated by default following replication fork arrest in the possibility that a cross-link is present. Lesions that cause replication fork arrest such as UV-associated adducts or radiation-induced DNA breaks can be repaired by other processes such as NER or ATM-mediated HR and do not require a functional FA pathway. A DNA cross-link may be unique in that efficient repair requires the coordination of more than one process (Fig. 6). First the cross-link must be excised from both DNA strands. Then the resultant double-strand DNA break must be repaired, a process that may involve the coordination of HR, TLS, and cell cycle checkpoint activation by the Fanconi pathway (Fig. 4). Failure to coordinate these processes may result in a specific hypersensitivity to cross-linking agents. 


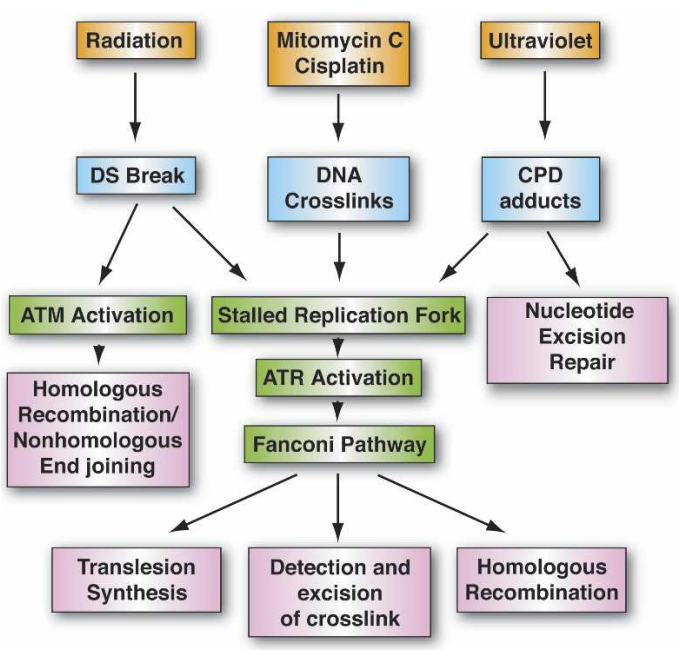

Figure 6. The FA pathway may function to specifically coordinate more than one pathway following cross-linking damage, whereas IR and UV damage can be repaired through other pathways.

\section{Conclusions}

Despite the recent advances in the understanding of the FA pathway, there are many aspects to the FA pathway that remain uncertain. Examples of questions that need answers are:

(1) Does ATR activate the FA pathway through phosphorylation of a component of complex 1 ?

(2) What are the purposes of the DNA processing functions of FANCM and FANCJ, and is the ATPase function of FANCM required for activation of the FA pathway?

(3) What is the role for BRIP1 in HR and is there a function interaction between BRCA1 and BRIP1 in mammalian cells following cross-linker damage?

(4) What is the endonuclease that excises cross-links, upstream of the FA pathway?

(5) How does the FA pathway participate in HR and TLS?

(6) Why is FA complex 1, the E3 ligase for FANCD2, a large, multiunit complex?

(7) Is the FA complex 1 or the deubiquitinating enzyme, USP1, the primary regulator of the FA pathway?

(8) Does complex 1 have a specific affinity for crosslink-damaged DNA?

(9) What is the E2 ubiquitin conjugating enzyme for the FA pathway?

(10) Are there other adult cancers associated with heterozygous mutation of FA genes?

(11) Are there cancers associated with single nuclear polymorphisms in FA genes?

The recent development of shRNA and siRNA screening libraries may help to answer some of these questions by identifying other components of the pathway (Brummelkamp and Bernards 2003).

It has now become apparent that abnormalities in the
FA pathway are not only found in childhood FA but also in the development of sporadic cancers in adults, where they may influence the response to chemotherapeutic agents. A better understanding of the pathway may allow the development of strategies to correct the pathway, thus preventing carcinogenesis in FA patients or those carrying a heterozygous mutation. Conversely, inhibitors of the pathway may be used as sensitizers to crosslinking chemotherapeutic agents in cancer treatment. It is evident that a better understanding of this complex pathway remains a priority for medical research.

\section{Acknowledgments}

We thank Hans Joenje, Weidong Wang, Kevin Hiom, and K.J. Patel for sharing data prior to publication. Funding bodies: Richard Kennedy: Susan G. Komen Breast Cancer Foundation; Alan D'Andrea: National Institutes of Health, Doris Duke Foundation.

\section{References}

Abraham, J., Lemmers, B., Hande, M.P., Moynahan, M.E., Chahwan, C., Ciccia, A., Essers, J., Hanada, K., Chahwan, R., Khaw, A.K., et al. 2003. Emel is involved in DNA damage processing and maintenance of genomic stability in mammalian cells. EMBO J. 22: 6137-6147.

Akkari, Y.M., Bateman, R.L., Reifsteck, C.A., D'Andrea, A.D., Olson, S.B., and Grompe, M. 2001. The 4N cell cycle delay in Fanconi anemia reflects growth arrest in late $\mathrm{S}$ phase. Mol. Genet. Metab. 74: 403-412.

Alter, B.P. 1996. Fanconi's anemia and malignancies. [Review]. Am. J. Hematol. 53: 99-110.

. 2003. Cancer in Fanconi anemia, 1927-2001. Cancer 97: 425-440.

Alter, B.P., Greene, M.H., Velazquez, I., and Rosenberg, P.S. 2003. Cancer in Fanconi anemia. Blood 101: 2072.

Amerik, A.Y. and Hochstrasser, M. 2004. Mechanism and function of deubiquitinating enzymes. Biochim Biophys Acta. 1695: 189-207.

Andreassen, P.R., D'Andrea, A.D., and Taniguchi, T. 2004. ATR couples FANCD2 monoubiquitination to the DNA-damage response. Genes \& Dev. 18: 1958-1963.

Auerbach, A.D. 1988. A test for Fanconi's anemia [letter]. Blood 72: 366-367.

Bagby Jr., G.C. 2003. Genetic basis of Fanconi anemia. Curr. Opin. Hematol. 10: 68-76.

Bartek, J., Lukas, C., and Lukas, J. 2004. Checking on DNA damage in S phase. Nat. Rev. Mol. Cell. Biol. 5: 792-804.

Bridge, W.L., Vandenberg, C.J., Franklin, R.J., and Hiom, K. 2005. The BRIP1 helicase functions independently of BRCA1 in the Fanconi anemia pathway for DNA crosslink repair. Nat. Genet. 37: 953-957.

Brosh Jr., R.M., Li, J.L., Kenny, M.K., Karow, J.K., Cooper, M.P., Kureekattil, R.P., Hickson, I.D., and Bohr, V.A. 2000. Replication protein A physically interacts with the Bloom's syndrome protein and stimulates its helicase activity. J. Biol. Chem. 275: 23500-23508.

Brummelkamp, T.R. and Bernards, R. 2003. New tools for functional mammalian cancer genetics. Nat. Rev. Cancer 3: 781789.

Bryant, H.E., Schultz, N., Thomas, H.D., Parker, K.M., Flower, D., Lopez, E., Kyle, S., Meuth, M., Curtin, N.J., and Helleday, 
T. 2005. Specific killing of BRCA2-deficient tumours with inhibitors of poly(ADP-ribose) polymerase. Nature 434: 913917.

Cantor, S.B., Bell, D.W., Ganesan, S., Kass, E.M., Drapkin, R., Grossman, S., Wahrer, D.C., Sgroi, D.C., Lane, W.S., Haber, D.A., et al. 2001. BACH1, a novel helicase-like protein, interacts directly with BRCA1 and contributes to its DNA repair function. Cell 105: 149-160.

Cantor, S., Drapkin, R., Zhang, F., Lin, Y., Han, J., Pamidi, S., and Livingston, D.M. 2004. The BRCA1-associated protein $\mathrm{BACH1}$ is a DNA helicase targeted by clinically relevant inactivating mutations. Proc. Natl. Acad. Sci. 101:23572362.

Carreau, M., Alon, N., Bosnoyan-Collins, L., Joenje, H., and Buchwald, M. 1999. Drug sensitivity spectra in Fanconi anemia lymphoblastoid cell lines of defined complementation groups. Mutat. Res. 435: 103-109.

Cass, I., Baldwin, R.L., Varkey, T., Moslehi, R., Narod, S.A., and Karlan, B.Y. 2003. Improved survival in women with BRCAassociated ovarian carcinoma. Cancer 97: 2187-2195.

Centurion, S.A., Kuo, H.R., and Lambert, W.C. 2000. Damageresistant DNA synthesis in Fanconi anemia cells treated with a DNA cross-linking agent. Exp. Cell. Res. 260: 216221.

Chan, J.Y., Becker, F.F., German, J., and Ray, J.H. 1987. Altered DNA ligase I activity in Bloom's syndrome cells. Nature 325: 357-359.

Chappuis, P.O., Goffin, J., Wong, N., Perret, C., Ghadirian, P., Tonin, P.N., and Foulkes, W.D. 2002. A significant response to neoadjuvant chemotherapy in BRCA1/2 related breast cancer. J. Med. Genet. 39: 608-610.

Condie, A., Powles, R.L., Hudson, C.D., Shepherd, V., Bevan, S., Yuille, M.R., and Houlston, R.S. 2002. Analysis of the Fanconi anaemia complementation group A gene in acute myeloid leukaemia. Leuk. Lymphoma 43: 1849-1853.

Couch, F.J., Johnson, M.R., Rabe, K., Boardman, L., McWilliams, R., de Andrade, M., and Petersen, G. 2005. Germ line Fanconi anemia complementation group $\mathrm{C}$ mutations and pancreatic cancer. Cancer Res. 65: 383-386.

D'Andrea, A.D. and Grompe, M. 2003. The Fanconi anaemia/ BRCA pathway. Nat. Rev. Cancer 3: 23-34.

D'Andrea, A. and Pellman, D. 1998. Deubiquitinating enzymes: A new class of biological regulators. Crit. Rev. Biochem. Mol. Biol. 33: 337-352.

de Winter, J.P., Waisfisz, Q., Rooimans, M.A., van Berkel, C.G., Bosnoyan-Collins, L., Alon, N., Carreau, M., Bender, O., Demuth, I., Schindler, D., et al. 1998. The Fanconi anaemia group G gene FANCG is identical with XRCC9. Nat. Genet. 20: 281-283.

de Winter, J.P., Leveille, F., van Berkel, C.G., Rooimans, M.A., van Der Weel, L., Steltenpool, J., Demuth, I., Morgan, N.V., Alon, N., Bosnoyan-Collins, L., et al. 2000a. Isolation of a cDNA representing the Fanconi anemia complementation group E gene. Am. J. Hum. Genet. 67: 1306-1308.

de Winter, J.P., Rooimans, M.A., van Der Weel, L., van Berkel, C.G., Alon, N., Bosnoyan-Collins, L., de Groot, J., Zhi, Y., Waisfisz, Q., Pronk, J.C., et al. 2000b. The Fanconi anaemia gene FANCF encodes a novel protein with homology to ROM. Nat. Genet. 24: 15-16.

Dhillon, V.S., Shahid, M., and Husain, S.A. 2004. CpG methylation of the FHIT, FANCF, cyclin-D2, BRCA2 and RUNX3 genes in Granulosa cell tumors (GCTs) of ovarian origin. Mol. Cancer 3: 33.

Donahue, S.L., Lundberg, R., Saplis, R., and Campbell, C. 2003. Deficient regulation of DNA double-strand break repair in Fanconi anemia fibroblasts. J. Biol. Chem. 278: 29487-29495.
Dronkert, M.L. and Kanaar, R. 2001. Repair of DNA interstrand cross-links. Mutat. Res. 486: 217-247.

Duckworth-Rysiecki, G. and Taylor, A.M. 1985. Effects of ionizing radiation on cells from Fanconi's anemia patients. Cancer Res. 45: 416-420.

Elledge, S.J. and Amon, A. 2002. The BRCA1 suppressor hypothesis: An explanation for the tissue-specific tumor development in BRCA1 patients. Cancer Cell 1: 129-132.

Farmer, H., McCabe, N., Lord, C.J., Tutt, A.N., Johnson, D.A., Richardson, T.B., Santarosa, M., Dillon, K.J., Hickson, I., Knights, C., et al. 2005. Targeting the DNA repair defect in BRCA mutant cells as a therapeutic strategy. Nature 434: 917-921.

Ford, D., Easton, D.F., Bishop, D.T., Narod, S.A., and Goldgar, D.E. 1994. Risks of cancer in BRCA1-mutation carriers. Breast Cancer Linkage Consortium. Lancet 343: 692-695.

Freie, B.W., Ciccone, S.L., Li, X., Plett, P.A., Orschell, C.M., Srour, E.F., Hanenberg, H., Schindler, D., Lee, S.H., and Clapp, D.W. 2004. A role for the Fanconi anemia C protein in maintaining the DNA damage-induced G2 checkpoint. I. Biol. Chem. 279: 50986-50993.

Friedberg, E.C., Wagner, R., and Radman, M. 2002. Specialized DNA polymerases, cellular survival, and the genesis of mutations. Science 296: 1627-1630.

Friedberg, E.C., Lehmann, A.R., and Fuchs, R.P. 2005. Trading places: How do DNA polymerases switch during translesion DNA synthesis? Mol. Cell 18: 499-505.

Garcia-Higuera, I., Kuang, Y., Denham, J., and D'Andrea, A.D. 2000. The Fanconi anemia proteins FANCA and FANCG stabilize each other and promote the nuclear accumulation of the Fanconi anemia complex. Blood 96: 3224-3230.

Garcia-Higuera, I., Taniguchi, T., Ganesan, S., Meyn, M.S., Timmers, C., Hejna, J., Grompe, M., and D'Andrea, A.D. 2001. Interaction of the Fanconi anemia proteins and BRCA1 in a common pathway. Mol. Cell 7: 249-262.

German, J., Schonberg, S., Caskie, S., Warburton, D., Falk, C., and Ray, J.H. 1987. A test for Fanconi's anemia. Blood 69: $1637-1641$.

Gordon, S.M. and Buchwald, M. 2003. Fanconi anemia protein complex: Mapping protein interactions in the yeast 2- and 3-hybrid systems. Blood 102: 136-141.

Gregory, R.C., Taniguchi, T., and D'Andrea, A.D. 2003. Regulation of the Fanconi anemia pathway by monoubiquitination. Semin. Cancer Biol. 13: 77-82.

Gupta, R., Sharma, S., Sommers, J.A., Jin, Z., Cantor, S.B., and Brosh Jr., R.M. 2005. Analysis of the DNA substrate specificity of the human BACH1 helicase associated with breast cancer. J. Biol. Chem. 280: 25450-25460.

Hahn, S.A., Greenhalf, B., Ellis, I., Sina-Frey, M., Rieder, H., Korte, B., Gerdes, B., Kress, R., Ziegler, A., Raeburn, J.A., et al. 2003. BRCA2 germline mutations in familial pancreatic carcinoma. J. Natl. Cancer Inst. 95: 214-221.

Helt, C.E., Cliby, W.A., Keng, P.C., Bambara, R.A., and O'Reilly, M.A. 2005. Ataxia telangiectasia mutated (ATM) and ATM and Rad3-related protein exhibit selective target specificities in response to different forms of DNA damage. J. Biol. Chem. 280: 1186-1192.

Hirano, S., Yamamoto, K., Ishiai, M., Yamazoe, M., Seki, M., Matsushita, N., Ohzeki, M., Yamashita, Y.M., Arakawa, H., Buerstedde, J.M., et al. 2005. Functional relationships of FANCC to homologous recombination, translesion synthesis, and BLM. EMBO J. 24: 418-427.

Houghtaling, S., Granville, L., Akkari, Y., Torimaru, Y., Olson, S., Finegold, M., and Grompe, M. 2005. Heterozygosity for p53 $\left(\operatorname{Trp} 53^{+/-}\right)$accelerates epithelial tumor formation in Fanconi anemia complementation group D2 (Fancd2) knockout 
mice. Cancer Res. 65: 85-91.

Howlett, N.G., Taniguchi, T., Olson, S., Cox, B., Waisfisz, Q., De Die-Smulders, C., Persky, N., Grompe, M., Joenje, H., Pals, G., et al. 2002. Biallelic inactivation of BRCA2 in Fanconi anemia. Science 297: 606-609.

Howlett, N.G., Taniguchi, T., Durkin, S.G., D'Andrea, A.D., and Glover, T.W. 2005. The Fanconi anemia pathway is required for the DNA replication stress response and for the regulation of common fragile site stability. Hum. Mol. Genet. 14: 693-701.

Hussain, S., Wilson, J.B., Medhurst, A.L., Hejna, J., Witt, E., Ananth, S., Davies, A., Masson, J.Y., Moses, R., West, S.C., et al. 2004. Direct interaction of FANCD2 with BRCA2 in DNA damage response pathways. Hum. Mol. Genet. 13: 1241-1248.

Joenje, H. and Patel, K.J. 2001. The emerging genetic and molecular basis of Fanconi anaemia. Nat. Rev. Genet. 2: 446457.

Jonnalagadda, V.S., Matsuguchi, T., and Engelward, B.P. 2005. Interstrand cross-link-induced homologous recombination carries an increased risk of deletions and insertions. DNA Repair (Amst.) 4: 594-605.

Karow, J.K., Chakraverty, R.K., and Hickson, I.D. 1997. The Bloom's syndrome gene product is a $3^{\prime}-5^{\prime}$ DNA helicase. J. Biol. Chem. 272: 30611-30614.

Kennedy, R.D., Quinn, J.E., Mullan, P.B., Johnston, P.G., and Harkin, D.P. 2004. The role of BRCA1 in the cellular response to chemotherapy. J. Natl. Cancer Inst. 96: 16591668.

King, M.C., Marks, J.H., and Mandell, J.B. 2003. Breast and ovarian cancer risks due to inherited mutations in BRCA1 and BRCA2. Science 302: 643-646.

Knudson Jr., A.G. 1971. Mutation and cancer: Statistical study of retinoblastoma. Proc. Natl. Acad. Sci. 68: 820-823.

Kobayashi, J., Antoccia, A., Tauchi, H., Matsuura, S., and Komatsu, K. 2004. NBS1 and its functional role in the DNA damage response. DNA Repair (Amst.) 3: 855-861.

Komori, K., Fujikane, R., Shinagawa, H., and Ishino, Y. 2002. Novel endonuclease in Archaea cleaving DNA with various branched structure. Genes Genet. Syst. 77: 227-241.

Kubbies, M., Schindler, D., Hoehn, H., Schinzel, A., and Rabinovitch, P.S. 1985. Endogenous blockage and delay of the chromosome cycle despite normal recruitment and growth phase explain poor proliferation and frequent edomitosis in Fanconi anemia cells. Am. J. Hum. Genet. 37: 1022-1030.

Kupfer, G., Naf, D., Garcia-Higuera, I., Wasik, J., Cheng, A., Yamashita, T., Tipping, A., Morgan, N., Mathew, C.G., and D'Andrea, A.D. 1999. A patient-derived mutant form of the Fanconi anemia protein, FANCA, is defective in nuclear accumulation. Exp. Hematol. 27: 587-593.

Kutler, D.I., Auerbach, A.D., Satagopan, J., Giampietro, P.F., Batish, S.D., Huvos, A.G., Goberdhan, A., Shah, J.P., and Singh, B. 2003a. High incidence of head and neck squamous cell carcinoma in patients with Fanconi anemia. Arch. Otolaryngol. Head Neck Surg. 129: 106-112.

Kutler, D.I., Singh, B., Satagopan, J., Batish, S.D., Berwick, M., Giampietro, P.F., Hanenberg, H., and Auerbach, A.D. 2003b. A 20-year perspective on the International Fanconi Anemia Registry (IFAR). Blood 101: 1249-1256.

Kutler, D.I., Wreesmann, V.B., Goberdhan, A., Ben-Porat, L., Satagopan, J., Ngai, I., Huvos, A.G., Giampietro, P., Levran, O., Pujara, K., et al. 2003c. Human papillomavirus DNA and p53 polymorphisms in squamous cell carcinomas from Fanconi anemia patients. J. Natl. Cancer Inst. 95: 1718-1721.

Lawley, P.D. and Phillips, D.H. 1996. DNA adducts from chemotherapeutic agents. Mutat. Res. 355: 13-40.
Levitus, M., Rooimans, M.A., Steltenpool, J., Cool, N.F., Oostra, A.B., Mathew, C.G., Hoatlin, M.E., Waisfisz, Q., Arwert, F., de Winter, J.P., et al. 2004. Heterogeneity in Fanconi anemia: Evidence for 2 new genetic subtypes. Blood 103: 2498-2503.

Levitus, M., Waisfisz, Q., Godthelp, B.C., De Vries, Y., Hussain, S., Wiegant, W.W., Elghabzouri-Maghrani, E., Steltenpool, J., Rooimans, M., Pals, G., et al. 2005. The DNA Helicase BRIP1 is defective in Fanconi anemia complementation group J. Nat. Genet. 37: 934-935.

Levran, O., Attwooll, C., Henry, R.T., Milton, K.L., Neveling, K., Rio, P., Batish, S.D., Kalb, R., Velleuer, E., Barral, S., et al. 2005. The BRCA1-interacting helicase BRIP1 is deficient in Fanconi Anemia. Nat. Genet. 39: 931-933.

Liede, A., Karlan, B.Y., and Narod, S.A. 2004. Cancer risks for male carriers of germline mutations in BRCA1 or BRCA2: A review of the literature. J. Clin. Oncol. 22: 735-742.

Litman, R., Peng, M., Jin, Z., Zhang, F., Zhang, J., Powell, S., Andreassen, P.R., and Cantor, S.B. 2005. BACH1 is critical for homologous recombination and appears to be the Fanconi anemia gene product FANCJ. Cancer Cell 8: 255-265.

Liu, Q., Guntuku, S., Cui, X.S., Matsuoka, S., Cortez, D., Tamai, K., Luo, G., Carattini-Rivera, S., DeMayo, F., Bradley, A., et al. 2000. Chk1 is an essential kinase that is regulated by Atr and required for the G(2)/M DNA damage checkpoint. Genes \& Dev. 14: 1448-1459.

Liu, T.X., Howlett, N.G., Deng, M., Langenau, D.M., Hsu, K., Rhodes, J., Kanki, J.P., D'Andrea, A.D., and Look, A.T. 2003. Knockdown of zebrafish Fancd2 causes developmental abnormalities via p53-dependent apoptosis. Dev. Cell 5: $903-$ 914.

Lomonosov, M., Anand, S., Sangrithi, M., Davies, R., and Venkitaraman, A.R. 2003. Stabilization of stalled DNA replication forks by the BRCA2 breast cancer susceptibility protein. Genes \& Dev. 17: 3017-3022.

Lo Ten Foe, J.R., Rooimans, M.A., Bosnoyan-Collins, L., Alon, N., Wijker, M., Parker, L., Lightfoot, J., Carreau, M., Callen, D.F., Savoia, A., et al. 1996. Expression cloning of a cDNA for the major Fanconi anaemia gene, FAA. Nat. Genet. 14: 320-323.

Marsit, C.J., Liu, M., Nelson, H.H., Posner, M., Suzuki, M., and Kelsey, K.T. 2004. Inactivation of the Fanconi anemia/BRCA pathway in lung and oral cancers: Implications for treatment and survival. Oncogene 23: 1000-1004.

Meetei, A.R., de Winter, J.P., Medhurst, A.L., Wallisch, M., Waisfisz, Q., van de Vrugt, H.J., Oostra, A.B., Yan, Z., Ling, C., Bishop, C.E., et al. 2003a. A novel ubiquitin ligase is deficient in Fanconi anemia. Nat. Genet. 35: 165-170.

Meetei, A.R., Sechi, S., Wallisch, M., Yang, D., Young, M.K., Joenje, H., Hoatlin, M.E., and Wang, W. 2003b. A multiprotein nuclear complex connects Fanconi anemia and Bloom syndrome. Mol. Cell. Biol. 23: 3417-3426.

Meetei, A.R., Levitus, M., Xue, Y., Medhurst, A.L., Zwaan, M., Ling, C., Rooimans, M.A., Bier, P., Hoatlin, M., Pals, G., et al. 2004. X-linked inheritance of Fanconi anemia complementation group B. Nat. Genet. 36: 1219-1224.

Meetei, A.R., Medhurst, A.L., Ling, C., Xue, Y., Singh, T.R., Bier, P., Steltenpool, J., Stone, S., Dokal, I., Mathew, C.G., et al. 2005. A human ortholog of archael DNA repair protein HEF is defective in Fanconi anemia complementation group M. Nat. Genet. 37: 958-963.

Mi, J. and Kupfer, G.M. 2005. The Fanconi anemia core complex associates with chromatin during S phase. Blood 105: 759766.

Miglierina, R., Le Coniat, M., and Berger, R. 1991. A simple diagnostic test for Fanconi anemia by flow cytometry. Anal. Cell. Pathol. 3: 111-118. 
Mosedale, G., Niedzwiedz, W., Alpi, A., Perrina, F., PereiraLeal, J., Johnson, M., Langevin, F., Pace, P., and Patel, K.J. 2005. The vertebrate Hef orthologue is a component of the Fanconi anemia tumour suppressor pathway. Nat. Struct. Mol. Biol. 12: 963-971.

Moynahan, M.E., Chiu, J.W., Koller, B.H., and Jasin, M. 1999. Brcal controls homology-directed DNA repair. Mol. Cell 4: $511-518$

Moynahan, M.E., Cui, T.Y., and Jasin, M. 2001a. Homologydirected DNA repair, mitomycin-c resistance, and chromosome stability is restored with correction of a Brcal mutation. Cancer Res. 61: 4842-4850.

Moynahan, M.E., Pierce, A.J., and Jasin, M. 2001b. BRCA2 is required for homology-directed repair of chromosomal breaks. Mol. Cell 7: 263-272.

Nakanishi, K., Taniguchi, T., Ranganathan, V., New, H.V., Moreau, L.A., Stotsky, M., Mathew, C.G., Kastan, M.B., Weaver, D.T., and D'Andrea, A.D. 2002. Interaction of FANCD2 and NBS1 in the DNA damage response. Nat. Cell. Biol. 4: 913-920.

Nakanishi, K., Yang, Y.G., Pierce, A.J., Taniguchi, T., Digweed, M., D'Andrea, A.D., Wang, Z.Q., and Jasin, M. 2005. Human Fanconi anemia monoubiquitination pathway promotes homologous DNA repair. Proc. Natl. Acad. Sci. 102: 11101115.

Narayan, G., Arias-Pulido, H., Nandula, S.V., Basso, K., Sugirtharaj, D.D., Vargas, H., Mansukhani, M., Villella, J., Meyer, L., Schneider, A., et al. 2004. Promoter hypermethylation of FANCF: Disruption of Fanconi Anemia-BRCA pathway in cervical cancer. Cancer Res. 64: 2994-2997.

Niedzwiedz, W., Mosedale, G., Johnson, M., Ong, C.Y., Pace, P., and Patel, K.J. 2004. The Fanconi anaemia gene FANCC promotes homologous recombination and error-prone DNA repair. Mol. Cell 15: 607-620.

Nijman, S.M., Huang, T.T., Dirac, A.M., Brummelkamp, T.R., Kerkhoven, R.M., D'Andrea, A.D., and Bernards, R. 2005. The deubiquitinating enzyme USP1 regulates the Fanconi anemia pathway. Mol. Cell 17: 331-339.

Okada, T., Sonoda, E., Yamashita, Y.M., Koyoshi, S., Tateishi, S., Yamaizumi, M., Takata, M., Ogawa, O., and Takeda, S. 2002. Involvement of vertebrate polк in Rad18-independent postreplication repair of UV damage. I. Biol. Chem. 277: 48690-48695.

Onclercq-Delic, R., Calsou, P., Delteil, C., Salles, B., Papadopoulo, D., and Amor-Gueret, M. 2003. Possible anti-recombinogenic role of Bloom's syndrome helicase in doublestrand break processing. Nucleic Acids Res. 31: 6272-6282.

Orelli, B.J., Logsdon Jr, J.M., and Bishop, D.K. 2001. Nine novel conserved motifs in BRCA1 identified by the chicken orthologue. Oncogene 20: 4433-4438.

Orlicky, S., Tang, X., Willems, A., Tyers, M., and Sicheri, F. 2003. Structural basis for phosphodependent substrate selection and orientation by the SCFCdc4 ubiquitin ligase. Cell 112: 243-256.

Pace, P., Johnson, M., Tan, W.M., Mosedale, G., Sng, C., Hoatlin, M., de Winter, J., Joenje, H., Gergely, F., and Patel, K.J. 2002. FANCE: The link between Fanconi anaemia complex assembly and activity. EMBO J. 21: 3414-3423.

Papadopoulo, D., Guillouf, C., Mohrenweiser, H., and Moustacchi, E. 1990a. Hypomutability in Fanconi anemia cells is associated with increased deletion frequency at the HPRT locus. Proc. Natl. Acad. Sci. 87: 8383-8387.

Papadopoulo, D., Guillouf, C., Porfirio, B., and Moustacchi, E. 1990b. Decreased mutagenicity in Fanconi's anemia lymphoblasts following treatment with photoactivated psoralens. Prog. Clin. Biol. Res. 340A: 241-248.
Pichierri, P. and Rosselli, F. 2004. The DNA cross-link-induced S-phase checkpoint depends on ATR-CHK1 and ATRNBS1-FANCD2 pathways. EMBO I. 23: 1178-1187.

Pichierri, P., Averbeck, D., and Rosselli, F. 2002. DNA crosslink-dependent RAD50/MRE11/NBS1 subnuclear assembly requires the Fanconi anemia C protein. Hum. Mol. Genet. 11: 2531-2546.

Poll, E.H., Arwert, F., Joenje, H., and Wanamarta, A.H. 1985. Differential sensitivity of Fanconi anaemia lymphocytes to the clastogenic action of cis-diamminedichloroplatinum (II) and trans-diamminedichloroplatinum (II). Hum. Genet. 71: 206-210.

Prakash, S. and Prakash, L. 2002. Translesion DNA synthesis in eukaryotes: A one- or two-polymerase affair. Genes \& Dev. 16: $1872-1883$.

Quinn, J.E., Kennedy, R.D., Mullan, P.B., Gilmore, P.M., Carty, M., Johnston, P.G., and Harkin, D.P. 2003. BRCA1 functions as a differential modulator of chemotherapy-induced apoptosis. Cancer Res. 63: 6221-6228.

Rebbeck, T.R., Lynch, H.T., Neuhausen, S.L., Narod, S.A., Van't Veer, L., Garber, J.E., Evans, G., Isaacs, C., Daly, M.B., Matloff, E., et al. 2002. Prophylactic oophorectomy in carriers of BRCA1 or BRCA2 mutations. N. Engl. I. Med. 346: 16161622.

Rischewski, J.R., Clausen, H., Leber, V., Niemeyer, C., Ritter, J., Schindler, D., and Schneppenheim, R. 2000. A heterozygous frameshift mutation in the Fanconi anemia $\mathrm{C}$ gene in familial T-ALL and secondary malignancy. Klin. Padiatr. 212: $174-176$.

Risinger, M.A. and Groden, J. 2004. Crosslinks and crosstalk: Human cancer syndromes and DNA repair defects. Cancer Cell 6: 539-545.

Rodriguez, M., Yu, X., Chen, J., and Songyang, Z. 2003. Phosphopeptide binding specificities of BRCAl COOH-terminal (BRCT) domains. J. Biol. Chem. 278: 52914-52918.

Ross, A.L., Simpson, L.J., and Sale, J.E. 2005. Vertebrate DNA damage tolerance requires the C-terminus but not BRCT or transferase domains of REV1. Nucleic Acids Res. 33: 12801289.

Rothfuss, A. and Grompe, M. 2004. Repair kinetics of genomic interstrand DNA cross-links: Evidence for DNA doublestrand break-dependent activation of the Fanconi anemia/ BRCA pathway. Mol. Cell. Biol. 24: 123-134.

Sala-Trepat, M., Rouillard, D., Escarceller, M., Laquerbe, A., Moustacchi, E., and Papadopoulo, D. 2000. Arrest of S-phase progression is impaired in Fanconi anemia cells. Exp. Cell. Res. 260: 208-215.

Shiloh, Y. 2001. ATM and ATR: Networking cellular responses to DNA damage. Curr. Opin. Genet. Dev. 11: 71-77.

Sridharan, D., Brown, M., Lambert, W.C., McMahon, L.W., and Lambert, M.W. 2003. Nonerythroid $\alpha \mathrm{II}$ spectrin is required for recruitment of FANCA and XPF to nuclear foci induced by DNA interstrand cross-links. J. Cell. Sci. 116: 823-835.

Strathdee, C.A., Duncan, A.M., and Buchwald, M. 1992a. Evidence for at least four Fanconi anaemia genes including FACC on chromosome 9. Nat. Genet. 1: 196-198.

Strathdee, C.A., Gavish, H., Shannon, W.R., and Buchwald, M. 1992b. Cloning of cDNAs for Fanconi's anaemia by functional complementation. Nature 356: 763-767. [Published erratum appears in Nature 1992 358: 434]

Taniguchi, T. and D'Andrea, A.D. 2002. The Fanconi anemia protein, FANCE, promotes the nuclear accumulation of FANCC. Blood 100: 2457-2462.

Taniguchi, T., Garcia-Higuera, I., Andreassen, P.R., Gregory, R.C., Grompe, M., and D'Andrea, A.D. 2002a. S-phase-specific interaction of the Fanconi anemia protein, FANCD2, 
with BRCA1 and RAD51. Blood 100: 2414-2420.

Taniguchi, T., Garcia-Higuera, I., Xu, B., Andreassen, P.R., Gregory, R.C., Kim, S.T., Lane, W.S., Kastan, M.B., and D'Andrea, A.D. 2002b. Convergence of the Fanconi anemia and ataxia telangiectasia signaling pathways. Cell 109: 459472.

Taniguchi, T., Tischkowitz, M., Ameziane, N., Hodgson, S.V., Mathew, C.G., Joenje, H., Mok, S.C., and D'Andrea, A.D. 2003. Disruption of the Fanconi anemia-BRCA pathway in cisplatin-sensitive ovarian tumors. Nat. Med. 9: 568-574.

Timmers, C., Taniguchi, T., Hejna, J., Reifsteck, C., Lucas, L., Bruun, D., Thayer, M., Cox, B., Olson, S., D'Andrea, A.D., et al. 2001. Positional cloning of a novel Fanconi anemia gene, FANCD2. Mol. Cell 7: 241-248.

Tischkowitz, M.D., Morgan, N.V., Grimwade, D., Eddy, C., Ball, S., Vorechovsky, I., Langabeer, S., Stoger, R., Hodgson, S.V., and Mathew, C.G. 2004. Deletion and reduced expression of the Fanconi anemia FANCA gene in sporadic acute myeloid leukemia. Leukemia 18: 420-425.

Tutt, A., Bertwistle, D., Valentine, J., Gabriel, A., Swift, S., Ross, G., Griffin, C., Thacker, J., and Ashworth, A. 2001. Mutation in Brca2 stimulates error-prone homology-directed repair of DNA double-strand breaks occurring between repeated sequences. EMBO J. 20: 4704-4716.

Vandenberg, C.J., Gergely, F., Ong, C.Y., Pace, P., Mallery, D.L., Hiom, K., and Patel, K.J. 2003. BRCA1-independent ubiquitination of FANCD2. Mol. Cell 12: 247-254.

van der Heijden, M.S., Brody, J.R., Gallmeier, E., Cunningham, S.C., Dezentje, D.A., Shen, D., Hruban, R.H., and Kern, S.E. 2004. Functional defects in the Fanconi anemia pathway in pancreatic cancer cells. Am. J. Pathol. 165: 651-657.

Wang, X., Andreassen, P.R., and D'Andrea, A.D. 2004. Functional interaction of monoubiquitinated FANCD2 and BRCA2/FANCD1 in chromatin. Mol. Cell. Biol. 24: 58505862.

Wilkinson, K.D. 2000. Ubiquitination and deubiquitination: Targeting of proteins for degradation by the proteasome. Semin. Cell. Dev. Biol. 11: 141-148.

Wu, L. and Hickson, I.D. 2002. The Bloom's syndrome helicase stimulates the activity of human topoisomerase III $\alpha$. Nucleic Acids Res. 30: 4823-4829.

Wyman, C., Ristic, D., and Kanaar, R. 2004. Homologous recombination-mediated double-strand break repair. DNA Repair (Amst.) 3: 827-833.

Xia, F. and Powell, S.N. 2002. The molecular basis of radiosensitivity and chemosensitivity in the treatment of breast cancer. Semin. Radiat. Oncol. 12: 296-304.

Xie, Y., de Winter, J.P., Waisfisz, Q., Nieuwint, A.W., Scheper, R.J., Arwert, F., Hoatlin, M.E., Ossenkoppele, G.J., Schuurhuis, G.J., and Joenje, H. 2000. Aberrant Fanconi anaemia protein profiles in acute myeloid leukaemia cells. Br. J. Haematol. 111: 1057-1064.

Yamamoto, K., Ishiai, M., Matsushita, N., Arakawa, H., Lamerdin, J.E., Buerstedde, J.M., Tanimoto, M., Harada, M., Thompson, L.H., and Takata, M. 2003. Fanconi anemia FANCG protein in mitigating radiation- and enzyme-induced DNA double-strand breaks by homologous recombination in vertebrate cells. Mol. Cell. Biol. 23: 5421-5430.

Yamashita, Y.M., Okada, T., Matsusaka, T., Sonoda, E., Zhao, G.Y., Araki, K., Tateishi, S., Yamaizumi, M., and Takeda, S. 2002. RAD18 and RAD54 cooperatively contribute to maintenance of genomic stability in vertebrate cells. EMBO $\mathrm{J}$. 21: 5558-5566.

Yang, Y.G., Herceg, Z., Nakanishi, K., Demuth, I., Piccoli, C., Michelon, J., Hildebrand, G., Jasin, M., Digweed, M., and Wang, Z.Q. 2005. The Fanconi anemia group A protein modulates homologous repair of DNA double-strand breaks in mammalian cells. Carcinogenesis 26: 1731-1740.

Yu, S.L., Johnson, R.E., Prakash, S., and Prakash, L. 2001. Requirement of DNA polymerase $\eta$ for error-free bypass of UVinduced CC and TC photoproducts. Mol. Cell. Biol. 21: 185188.

Yu, X., Chini, C.C., He, M., Mer, G., and Chen, J. 2003. The BRCT domain is a phospho-protein binding domain. Science 302: 639-642.

Zhong, Q., Chen, C.F., Li, S., Chen, Y., Wang, C.C., Xiao, J., Chen, P.L., Sharp, Z.D., and Lee, W.H. 1999. Association of BRCA1 with the hRad50-hMre11-p95 complex and the DNA damage response. Science 285: 747-750.

Zou, L. and Elledge, S.J. 2003. Sensing DNA damage through ATRIP recognition of RPA-ssDNA complexes. Science 300: $1542-1548$ 


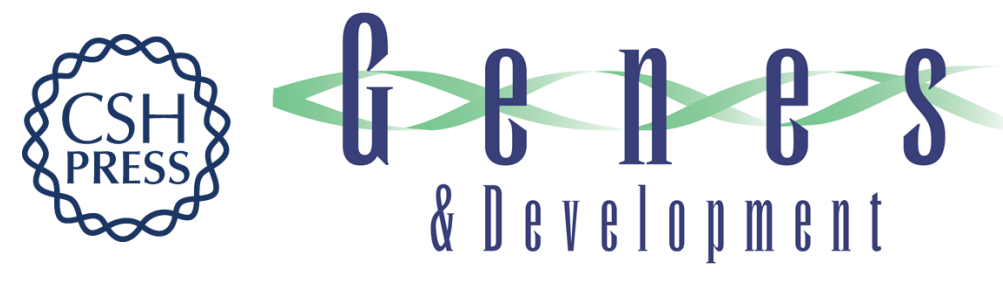

\section{The Fanconi Anemia/BRCA pathway: new faces in the crowd}

Richard D. Kennedy and Alan D. D'Andrea

Genes Dev. 2005, 19:

Access the most recent version at doi:10.1101/gad.1370505

References This article cites 135 articles, 51 of which can be accessed free at: http://genesdev.cshlp.org/content/19/24/2925.full.html\#ref-list-1

License

Email Alerting Receive free email alerts when new articles cite this article - sign up in the box at the top Service right corner of the article or click here.

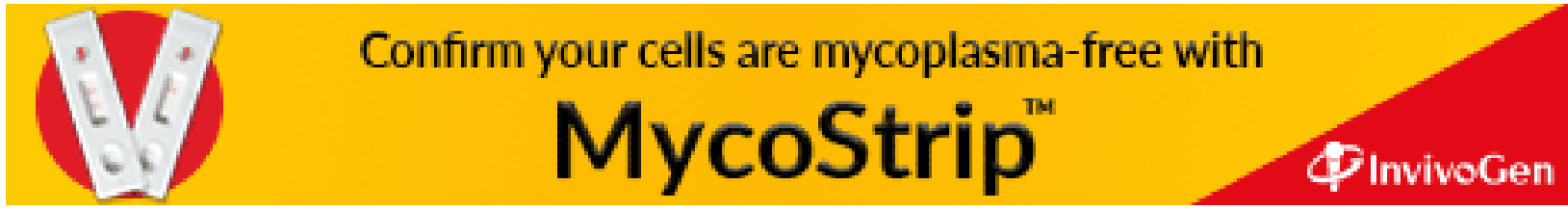

